\title{
Low-energy ion beamline scattering apparatus for surface science investigations
}

\author{
M. J. Gordon and K. P. Giapis ${ }^{\text {a) }}$ \\ Division of Chemistry and Chemical Engineering, California Institute of Technology, \\ Pasadena, California 91125
}

(Received 9 May 2005; accepted 14 June 2005; published online 28 July 2005)

\begin{abstract}
We report on the design, construction, and performance of a high current (monolayers/s), mass-filtered ion beamline system for surface scattering studies using inert and reactive species at collision energies below $1500 \mathrm{eV}$. The system combines a high-density inductively coupled plasma ion source, high-voltage floating beam transport line with magnet mass-filter and neutral stripping, decelerator, and broad based detection capabilities (ions and neutrals in both mass and energy) for products leaving the target surface. The entire system was designed from the ground up to be a robust platform to study ion-surface interactions from a more global perspective, i.e., high fluxes $\left(>100 \mu \mathrm{A} / \mathrm{cm}^{2}\right)$ of a single ion species at low, tunable energy $(50-1400 \pm 5 \mathrm{eV}$ full width half maximum) can be delivered to a grounded target under ultrahigh vacuum conditions. The high current at low energy problem is solved using an accel-decel transport scheme where ions are created at the desired collision energy in the plasma source, extracted and accelerated to high transport energy (20 keV to fight space charge repulsion), and then decelerated back down to their original creation potential right before impacting the grounded target. Scattered species and those originating from the surface are directly analyzed in energy and mass using a triply pumped, hybrid detector composed of an electron impact ionizer, hemispherical electrostatic sector, and $\mathrm{rf} / \mathrm{dc}$ quadrupole in series. With such a system, the collision kinematics, charge exchange, and chemistry occurring on the target surface can be separated by fully analyzing the scattered product flux. Key design aspects of the plasma source, beamline, and detection system are emphasized here to highlight how to work around physical limitations associated with high beam flux at low energy, pumping requirements, beam focusing, and scattered product analysis. Operational details of the beamline are discussed from the perspective of available beam current, mass resolution, projectile energy spread, and energy tunability. As well, performance of the overall system is demonstrated through three proof-of-concept examples: (1) elastic binary collisions at low energy, (2) core-level charge exchange reactions involving ${ }^{20} \mathrm{Ne}^{+}$with $\mathrm{Mg} / \mathrm{Al} / \mathrm{Si} / \mathrm{P}$ targets, and (3) reactive scattering of $\mathrm{CF}_{2}^{+} / \mathrm{CF}_{3}^{+}$off $\mathrm{Si}$. These studies clearly demonstrate why low, tunable incident energy, as well as mass and energy filtering of products leaving the target surface is advantageous and often essential for studies of inelastic energy losses, hard-collision charge exchange, and chemical reactions that occur during ion-surface scattering. (C) 2005 American Institute of Physics.
\end{abstract}

[DOI: 10.1063/1.1994987]

\section{INTRODUCTION}

Ion-surface interactions are important in a variety of fields such as plasma physics, surface analysis, materials growth (plasma-enhanced chemical vapor deposition and ion-beam assisted deposition), and semiconductor dry etching. In many of these application areas, collision energies are specifically kept below $1 \mathrm{keV}$ to have preferential energy deposition at the target surface only, i.e., short collision cascades to provide high selectivity to the topmost atomic layers without damaging the underlying material. This regime of energies $(<1 \mathrm{keV})$ represents an important window in the energy space of ion-surface interactions because many threshold processes occur at low energy (sputtering, core

\footnotetext{
a) Author to whom correspondence should be addressed; electronic mail: giapis@cheme.caltech.edu
}

shell electronic excitation, momentum-assisted desorption, secondary electron release, etc.). ${ }^{1,2}$ In addition, the kinetic energy of the incoming ion can even "activate" surfacespecific processes, allowing epitaxy at lower temperature, stimulation of surface reactions/adatom diffusion, synthesis of metastable material phases, ${ }^{3}$ and control of film density, texturing, and stress (for a review, see Ref. 1). However, the research literature on low energy ion-surface collisions is relatively sparse because of the experimental challenges associated with providing sufficient ion beam current at low impact energy for scattering, material growth, and etching studies. We have set out to probe this little-studied energy range by developing an ion beamline scattering system to investigate a wide variety of ion-surface interaction phenomena below $1 \mathrm{keV}$. This article describes the design and construction of our system and its application to three proof-of- 


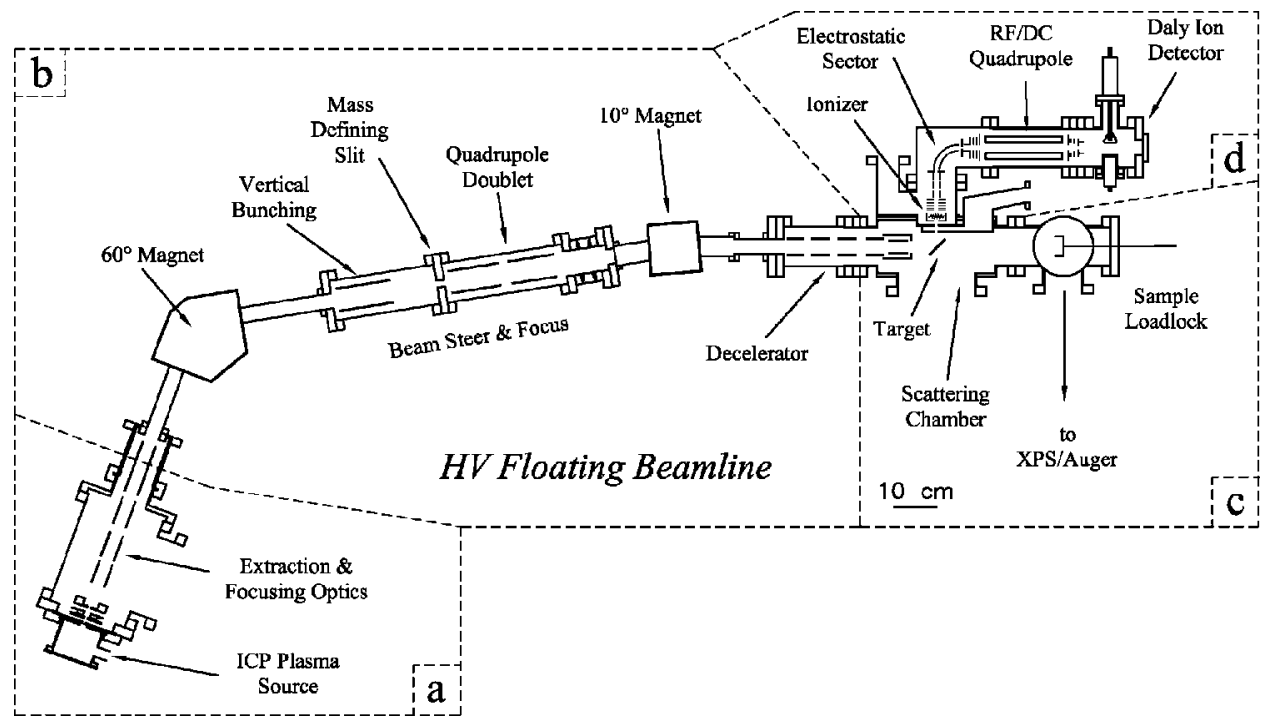

FIG. 1. Schematic of the low-energy ion beamline scattering apparatus showing various sections: (a) ICP plasma source and extraction optics, (b) high-voltage floating region including both steering magnets and decelerator, (c) scattering chamber, and (d) scattered product detector.

concept examples: elastic binary collisions at low energy, core-shell charge exchange collisions involving $\mathrm{Ne}^{+}$, and reactive scattering of $\mathrm{CF}_{3}^{+} / \mathrm{CF}_{2}^{+}$off $\mathrm{Si}$.

Our design philosophy has been to take an inductively coupled plasma (ICP) source and couple it to a high-voltage ion beam transport line with magnetic mass filtering to provide a clean ion beam surface probe with high current $\left(>100 \mu \mathrm{A} / \mathrm{cm}^{2}\right)$ and tunable energy $(\sim 50 \mathrm{eV}-1 \mathrm{keV})$. Space charge repulsion between the ions, which usually precludes high current at low energy, is circumvented using the accel-decel scheme for transport. In this arrangement, ions are created at the desired collision energy in the plasma source, extracted and accelerated to high transport energy (to fight space charge repulsion), and then decelerated back down to their original creation potential right before impacting the grounded target. In this way, the beam current is high, the collision energy is easily tunable (by floating the plasma source above ground), and the target is always kept grounded. The ICP-based beamline is a generic and robust system because any ion created in the plasma can be individually singled out and delivered to the target as a clean surface probe composed of only one species and one charge state. Species scattered by or originating from the target surface are analyzed with a hybrid detector which allows simultaneous mass and energy filtering — so the kinematics, charge exchange, and chemistry which occurs upon scattering can be investigated.

\section{DESCRIPTION OF THE INSTRUMENT}

The low-energy, ion beamline scattering system is shown schematically in Fig. 1, with technical specifications given in Table I. The system is composed of four main sections: (a) ICP ion source with extraction optics; (b) high voltage beamline with magnetic mass filter, focusing elements, and deceleration optics; (c) scattering chamber; and (d) scattered product detector. Specific construction details of each section of the instrument can be found elsewhere. ${ }^{4}$ The design philosophy of the beamline was to provide high fluxes $\left(>100 \mu \mathrm{A} / \mathrm{cm}^{2}\right)$ of a single ion species at low impact energy $[50-1400 \pm 5 \mathrm{eV}$ full width half maximum (FWHM)] onto a grounded target to facilitate ultrahigh vacuum (UHV) scattering studies using both inert and reactive beams. Space charge repulsion is controlled by transporting the ions at high voltage, with mass filtering, beam steer, and quality adjustments all occurring on the accelerated beam.

The particle flux from the target is analyzed with a triple-differentially pumped hybrid detector with both energy and mass dispersion. This system combines an electron impact ionizer, hemispherical electrostatic sector, and quadrupole mass filter in series with single ion counting on the rear end so that small signals of both ions and neutrals can be analyzed. With such a scheme, the collision kinematics, charge exchange, and chemistry occurring on the target surface can be separated by fully analyzing the scattered product flux. In the next few sections, key design aspects of the plasma source, beamline, and scattering system are emphasized to highlight why low-energy ion beam experiments are so demanding and how to work around physical limitations associated with high beam flux at low energy, pumping requirements, beam focusing, and scattered product detection.

\section{A. Design philosophy}

As inferred in the introduction, a high-current ion beam cannot be exposed to decelerating fields during transport, otherwise it will diverge. Unfortunately, space charge repulsion between the ions can only be "controlled" using high transport energy (Langmuir-Child law), ${ }^{5}$ continual refocusing, ${ }^{6}$ or by artificially neutralizing the beam by adding electrons externally (see Lawson ${ }^{7}$ ). The latter two options are usually reserved for very high current beams (mA) used in particle accelerators. On the laboratory scale, continual refocusing is cumbersome and usually limited to highly symmetric systems (without a mass filter); as well, artificial neutralization is not an option because a neutralized beam cannot be mass filtered. The solution is therefore simple-just transport and mass filter the beam at high ac- 
TABLE I. Design and operational specifications for the low-energy ion beamline scattering system.

\begin{tabular}{|c|c|}
\hline Ion source & Inductively coupled plasma, 2-turn solenoid, $1 \mathrm{~kW} @ 13.56 \mathrm{MHz}$ \\
\hline Source pressure & $0.5-10$ mTorr \\
\hline Beamline acceleration voltage & $10-20 \mathrm{keV}$ \\
\hline Magnetic mass filter & $\begin{array}{l}60^{\circ}, 300 \mathrm{~mm} \text { radius of curvature, } 50 \mathrm{~mm} \text { air gap } \\
\sim 0.8 \mathrm{~T} \text { max field, water cooled, } 300 \mathrm{~V}-16 \text { A supply } \\
\text { Field stability: Hall feedback, } \pm 3 \mathrm{G}\end{array}$ \\
\hline $\begin{array}{l}\text { Ion deflector magnet } \\
\text { (fast neutral removal) }\end{array}$ & $\begin{array}{l}10^{\circ}, 1300 \mathrm{~mm} \text { radius of curvature, } 50 \mathrm{~mm} \text { gap } \\
\sim 1800 \mathrm{G} \text { max field, } 600 \mathrm{~V}-2 \mathrm{~A} \text { supply }\end{array}$ \\
\hline Extractor & four elements ( 1 floating extraction electrode +3 biased separately) \\
\hline Beam shaping & $\begin{array}{l}\text { four element asymmetric Einzel (before } 60^{\circ} \text { magnet) } \\
Y \text {-axis divergence corrector (after } 60^{\circ} \text { magnet) } \\
\text { dc quadrupole doublet (eight elements - after mass defining slit) }\end{array}$ \\
\hline Decelerator & Asymmetric Einzel triplet + steering quadrupole + guard electrode \\
\hline Beam energy & $\sim 20-1500$ eV \pm 5 eV FWHM (maximum) (measured @ target with electrostatic sector) \\
\hline Beam size & $1-3 \mathrm{~mm}$ diameter, tunable \\
\hline Beam current & $250 \mu \mathrm{A} / \mathrm{cm}^{2} \mathrm{Ar}^{+} @ 50 \mathrm{eV}, 150 \mu \mathrm{A} / \mathrm{cm}^{2} \mathrm{O}_{2}^{+} @ 50 \mathrm{eV}$ \\
\hline Scattering chamber pressure & $<1 \times 10^{-8}$ Torr (beam on @ $500 \mu \mathrm{A} / \mathrm{cm}^{2}$, plasma source @ 5 mTorr) \\
\hline Scattered product detector & $\begin{array}{l}\text { Electron impact ionizer-10 mA emission } \\
90^{\circ} \text { hemispherical sector filter with Herzog plates, } 58 \mathrm{~mm} \text { radius } \\
\mathrm{rf} / \mathrm{dc} \text { quadrupole: } 19 \mathrm{~mm} \text { diam poles @ } 2.22 \mathrm{MHz}, 300 \mathrm{~W}\end{array}$ \\
\hline Ion counter & $\begin{array}{l}\text { Daly-type conversion dynode @ }-15-30 \mathrm{keV} \\
\text { Fast organic scintillator+PMT tube (in vacuum) }\end{array}$ \\
\hline Other facilities & $\begin{array}{l}\text { Sputter cleaning, anneal to } 900^{\circ} \mathrm{C}, \mathrm{Ar}^{+} \text {SIMS (scattering chamber) } \\
\text { XPS (in-vacuum transfer) }\end{array}$ \\
\hline
\end{tabular}

celeration voltage. ${ }^{8-11}$ What one desires is a symmetric (usually cylindrical), pumpable, high-voltage "shield" around the ion beam column throughout the beam transport line (including the mass filter) while working with a grounded target. This situation is experimentally demanding because it requires a pumpable high-voltage envelope around the propagating ion beam to shield it from the grounded beamline chambers which maintain the vacuum. Such an approach has been used successfully for a $10 \mathrm{keV}$ beamline by constructing an electrostatic mesh chamber inside a grounded vacuum shell. ${ }^{3}$ We have taken a different approach whereby the entire vacuum system itself (chambers, valves, feedthrus, etc.) is floating below ground at the beam transport energy $(-20 \mathrm{keV})$. This philosophy avoids all the problems associated with high-voltage isolation inside vacuum where space is tight and pumping conductance must be maximized. All the isolation problems are brought outside of vacuum and we can avoid making a chamber within a chamber.

The high-voltage floating section of our beamline system, shown in Fig. 1, extends from the end of the premagnet Einzel triplet up to and including the decelerator where it joins to the grounded scattering chamber. The floating section includes the $60^{\circ}$ sector magnet, mass slit, quadrupole doublet, $10^{\circ}$ steering magnet, and decelerator. Electrical breaks are used at both ends to isolate the floating section from the rest of the system with the premagnet Einzel triplet (lens number 3 ) and decelerator (lens numbers 2 and 3 ) functioning as transfer lenses to shield the beam between sections. The vacuum chambers themselves are supported using a poly-vinyl chloride scaffold system to stand off the floating potential and the vacuum pumps (CT7 cryopump after the $60^{\circ}$ sector, $200 \mathrm{~L} / \mathrm{s}$ turbo on the quadrupole doublet) are also isolated with electrical breaks.

\section{B. ICP plasma source and ion beam extraction}

One of the most important choices in any beamline design is the ion source itself. The source should have high conversion efficiency, low operating pressure (to avoid gas loading the beamline), well-defined ion creation potential, narrow ion energy spread, and compatibility with both inert and reactive working gases. Traditionally, Freeman-type, low-voltage dc arcs have been the ion source of choice because of their high current and low pressure operation. $3,12,13$ However, arc sources require frequent filament changes (a few tens of hours for high beam currents) and contaminate the beam with useless ions resulting from reaction of the working gas with the hot filament used to sustain the discharge. We have solved these problems by designing an ICP source and extraction system for our beamline which can satisfy all the above criteria along with clean, sustained operation-even with corrosive working gases. The inductive coupling scheme is ideal because it can provide high ion density $\left(10^{11}-10^{13} / \mathrm{cm}^{3}\right)$ with low plasma potential $(<20 \mathrm{eV})$ and narrow ion energy spread $(2-5 \mathrm{eV})$, all at low working pressure (0.1-5 mTorr) (for a summary of ICPs, see Refs. 5 and 14).

A schematic of the ICP plasma reactor and extraction electrode system is shown in Fig. 2. The plasma reactor is constructed from a 4 in.o.d. $\times 4$ in. alumina tube (a Pyrex version is also used) with alumina end caps sealed by o-rings to an 8 in. Conflat flange fitted to the front of the beamline. The plasma is excited by a two-turn, rf-solenoid antenna excited through a $\Pi$ network at $13.56 \mathrm{MHz}$. A grounded, copper Faraday shield (similar to Ref. 15) is situated between the antenna and reactor to eliminate all capacitive coupling between the plasma and rf antenna. It is imperative that ca- 


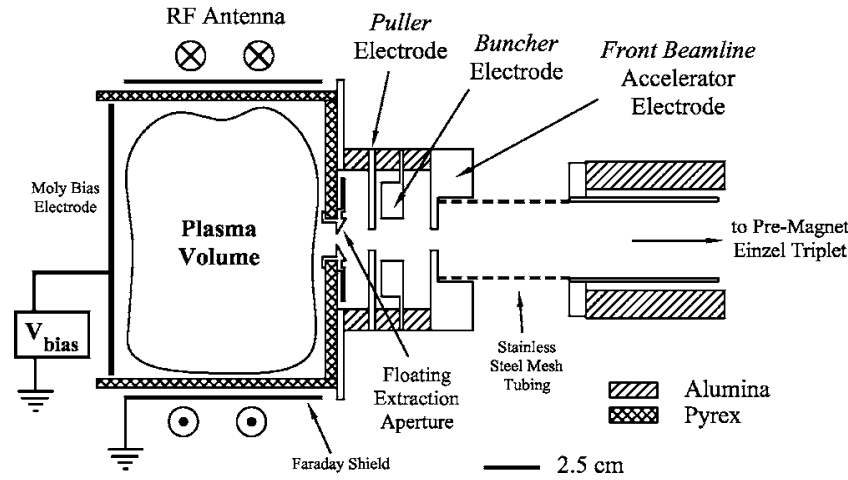

FIG. 2. Design schematic of the ICP plasma source and ion beam extraction electrodes. Both the reactor and electrode set have cylindrical symmetry. The extraction aperture where the virtual plasma sheath forms is electrically floating with the plasma itself. Also, two versions of the plasma reactor (pyrex and alumina) were used.

pacitive coupling be minimized to keep the plasma potential low $(<20 \mathrm{~V})$ and ion energy distribution narrow. ${ }^{14}$ The entire plasma volume can be floated above ground by an internal molybdenum bias electrode ( $\mathrm{Ti}$ and $\mathrm{Ta}$ were also used, depending on the plasma chemistry) connected to a dc supply which sets the final beam energy. Operating pressures are typically 1-5 mTorr for input powers ranging from 300 to $800 \mathrm{~W}$. In addition, highly electronegative gases $\left(\mathrm{CF}_{4}, \mathrm{O}_{2}\right)$ were frequently blended with small amounts of Ar to provide sufficient electrons for good inductive coupling and power transfer from antenna to plasma. Mixing gases in the source is not a great concern because the beam is mass filtered downstream.

The ion beam (plasma beam) is extracted from the ICP source through a floating extraction aperture $(5 \mathrm{~mm}$ sharpedged hole, $120^{\circ}$ bevel) and triode accel-decel lens system (for example, see Refs. 16 and 17). Smooth field variation in the vicinity of the "virtual" sheath of the plasma is necessary to form a uniform cross section ion beam column. ${ }^{17}$ In close proximity are three cylindrically symmetric electrostatic lenses in series (puller, buncher, and front beamline accel electrodes) with tantalum cover plates to prevent excessive sputtering. The final design for the extractor electrode system was the result of both space charge simulations $\left(\right.$ SIMION $\left.^{18}\right)$ as well as extensive operational testing. The front beamline electrode is the main acceleration step and is joined to the premagnet Einzel triplet (see next section) through stainless steel mesh tubing. Since the gas load to the beamline is of paramount importance, the extractor was design to be as "open" as possible to maximize pumping, so that background gas collisions are minimized. A $1000 \mathrm{~L} / \mathrm{s}$ drag turbo directly below the extractor functions as the main differential pumping step, keeping the extraction chamber at $5 \times 10^{-6}$ Torr with the plasma source running at 5 mTorr.

\section{High voltage beamline}

After the ion beam is extracted from the plasma and accelerated to $\sim 20 \mathrm{keV}$ by the front beamline electrode, the beam waist is adjusted by an Einzel triplet to coincide with the source point of the magnetic sector field. In this way, angular divergence of the beam at the source point is auto- matically removed by the sector field when the pass mass is refocused after the magnet at the field image point (the mass slit). ${ }^{17,19}$ The $60^{\circ}$ sector magnet has 8 in. diam poles, hexagonal shoes, $50 \mathrm{~mm}$ air gap to allow clearance for the beamline flight tube (1.5 in. o.d., floating at $-20 \mathrm{keV}$, insulated by mica sheets), and adjustable mass slit (0-13 mm wide $\times 18 \mathrm{~mm}$ high) downstream. Since the air gap was not small compared to the shoe height (and pole size), a significant fringe field extended beyond the physical pole boundaries. As such, it was necessary to account for the "virtual" pole boundaries using an extended fringe field method ${ }^{20,21}$ to calculate the effective radius of curvature $(\sim 11 \mathrm{in}$. instead of 8 in., as given by the pole diameter). In addition, it was absolutely necessary to actively control the magnet at $\sim 10 \mathrm{~Hz}$ with Hall probe feedback to keep the ion beam from drifting on the target. With this system, the field could be held within $\pm 3 \mathrm{G}$ with the magnet at maximum strength $(\sim 0.8 \mathrm{~T})$.

One should note that a magnetic sector with parallel pole shoes does not produce a stigmatic image of the source point. ${ }^{17}$ Such an effect manifests as an ion beam which enters the magnet having circular cross section, but leaves the field elongated in the nondispersive $(Y)$ direction as an ellipse with less on-axis brightness. ${ }^{17}$ Stigmatic focusing with a sector usually requires tilting the pole shoes to create a slightly inhomogeneous field in the radial direction to offset the radius of curvature for different flight paths. The lack of a stigmatic image was not deemed so critical in our design; however, the loss of current due to divergence in the $Y$ direction was considered important. Therefore, a weak electrostatic "bunching" field in the $Y$ direction $(+500-1000 \mathrm{~V}$ off the beamline floating potential) after the magnet was added to recover the otherwise lost beam current rather than tilting the pole shoes.

When the ion beam passes through the mass slit, it exhibits a crossover point in the dispersive direction $(X)$, but an elliptic cross section in the nondispersive direction $(Y)$. Unfortunately, the sector removes the inherent cylindrical symmetry of the ion beam as extracted from the plasma because of the field "handedness." Since it is desirable to decelerate a symmetric, parallel beam having circular cross section and small waist, we felt that an additional focusing step was necessary after the mass slit. A dc quadrupole doublet was used in the drift space between the mass slit and decelerator to affect the symmetry correction. A quadrupole field was chosen because its planar symmetry seemed better suited to fix unequal divergences of the beam in the $X$ and $Y$ axes. In addition, a quadrupole field provides stronger focusing action and is shorter overall than an axially symmetric lens system. ${ }^{7}$ The doublet is operated with $Y$ correction first, followed by $X$ (first quad - $\pm Y$ plates variable, second quad - $\pm X$ plates variable) with the plate voltages derived from power supplies floating on the beamline acceleration potential.

It is well known that collisions of energetic ions with background gas atoms can generate fast neutrals through charge exchange processes. ${ }^{22,23}$ In fact, fast neutral beams are produced using this method by sending a fast ion beam through a charge exchange cell containing background gas. The process of fast neutral generation, although much less significant in our system, could possibly influence scattering 


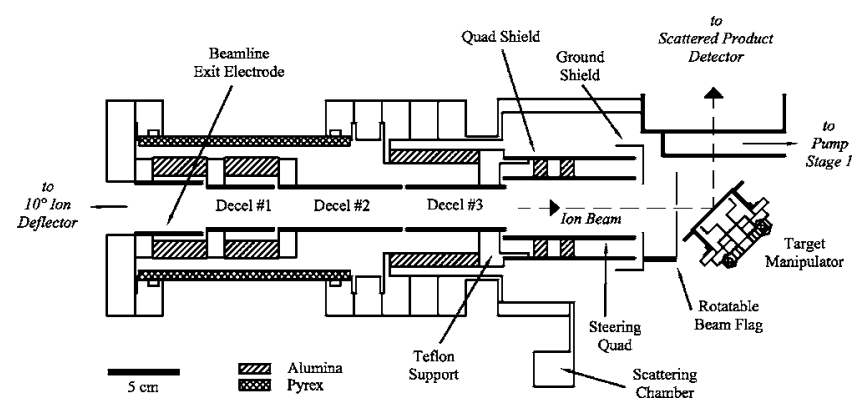

FIG. 3. Design schematic of the ion beam decelerator, high-voltage beamline electrical break, and target region.

results. Since it is extremely difficult to measure fast neutrals quantitatively, we have therefore taken the approach to rid the beam of fast neutrals on purpose, even if they may not exist to a significant degree in our system. This is simply done by deflecting the ion beam $10^{\circ}$ with a small magnetic sector field right before the decelerator entrance so that any fast neutrals in the upstream beam are not within line of sight of the target. The short flight distance through the decelerator to the sample is unimportant because this region is held at high vacuum conditions $\left(1 \times 10^{-8}\right.$ Torr $)$. The small sector has square pole shoes, 2 in. air gap, and gives a $10^{\circ}$ deflection to the ion beam with $\sim 1300 \mathrm{~mm}$ turning radius. Since the deflection is small and the curvature radius extremely large, the beam symmetry is not disturbed to any great extent.

\section{Deceleration}

Deceleration lens schemes for high-energy ion beams have traditionally been approached from two very different points of view. Experiments using ion implanters $(>50 \mathrm{keV}$ transport energy, mA currents) have demonstrated that ultrashort, extremely strong slowing fields $(50 \mathrm{kV}$ in $10-20$ $\mathrm{mm}$ ) using two or three thin electrostatic lenses provide the best spots. ${ }^{13,24,25}$ On the other hand, $\mu \mathrm{A}$ beam currents at lower transport energies are more successfully dealt with using longer, more complex schemes (3-6 tube-like electrodes). ${ }^{26-29}$ Our decel system is rather simple (Fig. 3) with an asymmetric Einzel triplet (short-long-short) followed by a large inner diameter, short quadrupole with a grounded end cap to shield the target from any high-voltage fields. The Number 2 and 3 lenses of the triplet are run more negative than lens Number 1 to pinch the beam after a first stage of slowing occurs between the main beamline and decel Number 1. It is thought that the potential drop of a few $\mathrm{kV}$ in this region (between decel Numbers 1 and 2) aids in neutralizing the beam space charge for the rest of the deceleration because slow electrons are trapped in the beam channel. ${ }^{27}$ The end of decel Number 3 and the entire quad extend into the grounded scattering chamber. The quadrupole exit setup for final beam steer is short and stubby so the field asymmetries near its plate electrodes are so far away from the bunched beam that they are irrelevant. Operation of the quad is very weak with only $200-400 \mathrm{~V}$ of asymmetric steer capability on a centerline floating potential of -6 to $-10 \mathrm{kV}$. A floating circular shield encloses the quad to screen the beam from the grounded walls of the scattering chamber. The quad shield,

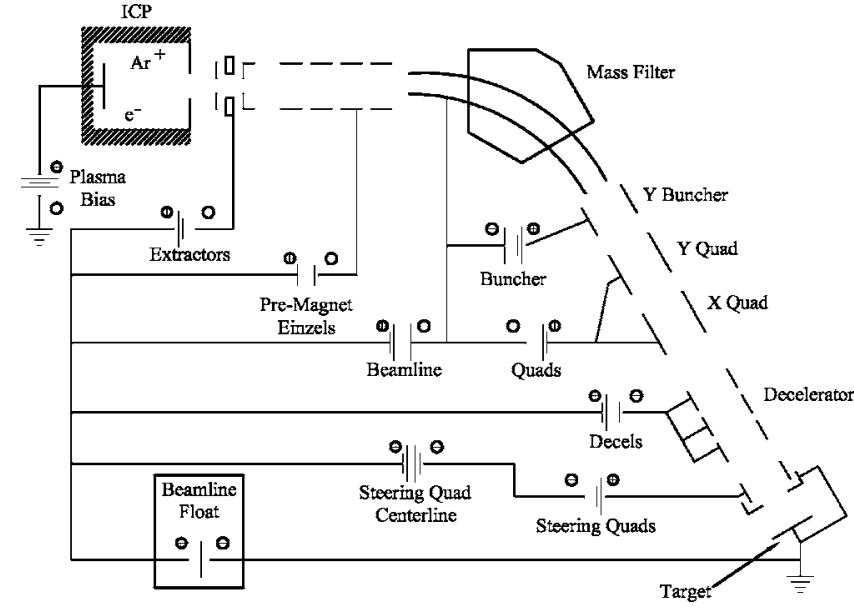

FIG. 4. Simplified schematic of the power supply bias scheme for the beamline. All acceleration, focusing, and steering lens supplies float atop the main beamline bias $(20-1500 \mathrm{eV})$ which controls the final impact energy. A separate plasma bias supply is ramped up in direct correspondence with the beamline float bias.

quad centerline float, and the four steering plates are all independently adjustable. Finally, a fully grounded end cap over the quad exit shields the target from any high-voltage fields.

\section{E. Beamline bias scheme}

Due to the "floating beamline" design principle, it was deemed easier to adopt a floating power supply bias scheme for the focusing elements on the HV section. In this design, smaller, more accurate supplies float on the main beamline bias voltage to provide fine beam steering control. A schematic of this system is shown in Fig. 4. In addition, all beamline power supplies (except the plasma bias) float on top of a separate dc supply that is ramped up identically with the plasma bias voltage. In this way, exactly the same extraction and focus conditions with respect to earth occur for all beam energies. It is necessary to separate these two voltages because the $13.56 \mathrm{MHz}$ noise from the plasma electron oscillation causes havoc in the regulator circuits for the rest of the beamline power supplies. Incidentally, this oscillation is too high in frequency to affect the inherent ion beam self-neutralization. ${ }^{3}$ Also, the vertical bunching plates and quadrupole doublet float on the beamline high voltage $(-15-20 \mathrm{kV})$ while the steering quad supplies and quad shield float atop the steering quad centerline potential $(-6-10 \mathrm{kV})$.

\section{F. Scattering chamber}

The UHV scattering chamber was custom built in-house to have two pumping stages mounted inside the overall chamber to differentially pump the scattered product beam leaving the target. Each stage has a $2 \mathrm{~mm}$ diam skimmer and its own dedicated turbopump. Also, a capacitor deflector is situated between the two stages so charged species can be removed from the scattered product signal if desired. The target sample rests on a five-axis goniometer with heating to $900{ }^{\circ} \mathrm{C}$ and scattering experiments are usually carried out at a $90^{\circ}$ lab angle in specular reflection. The scattering chamber 
itself is pumped by a CT8 cryopump and $1300 \mathrm{~L} / \mathrm{s}$ maglev turbopump to maintain the pressure in the $10^{-9}$ Torr range during bombardment at maximum beam current.

For specular reflection and $90^{\circ}$ lab angle, the target is inclined $45^{\circ}$ from the beam propagation axis. With low energy beams, it is well documented that an inclined target can have significant impact on the actual versus "desired" scattering angle as the incident beam energy is varied. ${ }^{30}$ To avoid this problem, a rotatable, tantalum beam flag with $2 \mathrm{~mm}$ diam hole is place directly in front of the target as a shield, perpendicular to the beam propagation axis. In this way, the beam sees a totally symmetric decelerating field, rather than the inclined target. Thus, the target angle does not modify the overall lab scattering angle for different incident beam energies (see Sec. III for verification of this fact). In addition, the current on both the beam flag and target can be monitored separately to tune the ion beam steering and focus.

Finally, the scattering chamber is outfit with a miniature $180^{\circ}$ hemispherical sector energy analyzer that can be moved into and out of the beam path directly at the target position to measure the incident beam energy distribution for every incident beam condition. The analyzer is $\sim 23 \mathrm{~mm}$ radius with Herzog corrector plates, inlet Einzel triplet, and channeltron detector.

\section{G. Scattered product detector}

The most idealized scattering experiment would involve the detection of all species leaving the target surface, both ions and neutrals, within the space of mass and energy. This scheme would allow the kinematics, charge exchange, and chemistry of scattering phenomena to be separated. Toward this goal, our detection system combines an electron impact ionizer, electrostatic sector energy filter, and high transmittance $\mathrm{rf} / \mathrm{dc}$ quadrupole mass filter with an extremely sensitive ion counting system. Figure 5(a) shows a simplified schematic of the detector system. We believe the electrostatic sector with sequential quad provides several advantages over traditional time-of-flight (TOF) techniques: (1) the sector can be placed very close to the sample surface; (2) energy analysis does not require beam chopping; (3) energy and mass dispersion are separated inherently; and (4) it is easy to implement an electron impact ionization scheme to detect low energy neutrals (TOF requires $E_{\text {neutral }}>1-3 \mathrm{keV}$ for direct detection with a microchannel plate).

The design of the scattered product detector was based on the ionizer and pole set (19 $\mathrm{mm}$ diameter) from an Extrel QPS system, with the electrostatic energy filter, transfer optics, and ion counting system designed and fabricated inhouse. The ionizer has a Whetstone bridge filament structure with axial entrance and ion extraction, along with five lens elements after the grid to enable different extraction modes. Specifically, the ionization volume size and ion creation potential can be easily changed by tailoring the grid, extractor, and focus plate voltage ratios. This is a very important point because any variation in ion creation potential in the ionizing volume (most ionizers have this problem) causes an artificial linewidth in the energy spectrum. We made specific intent to minimize this effect by fully characterizing our ionizer system. Experiments with the electrostatic sector show that the
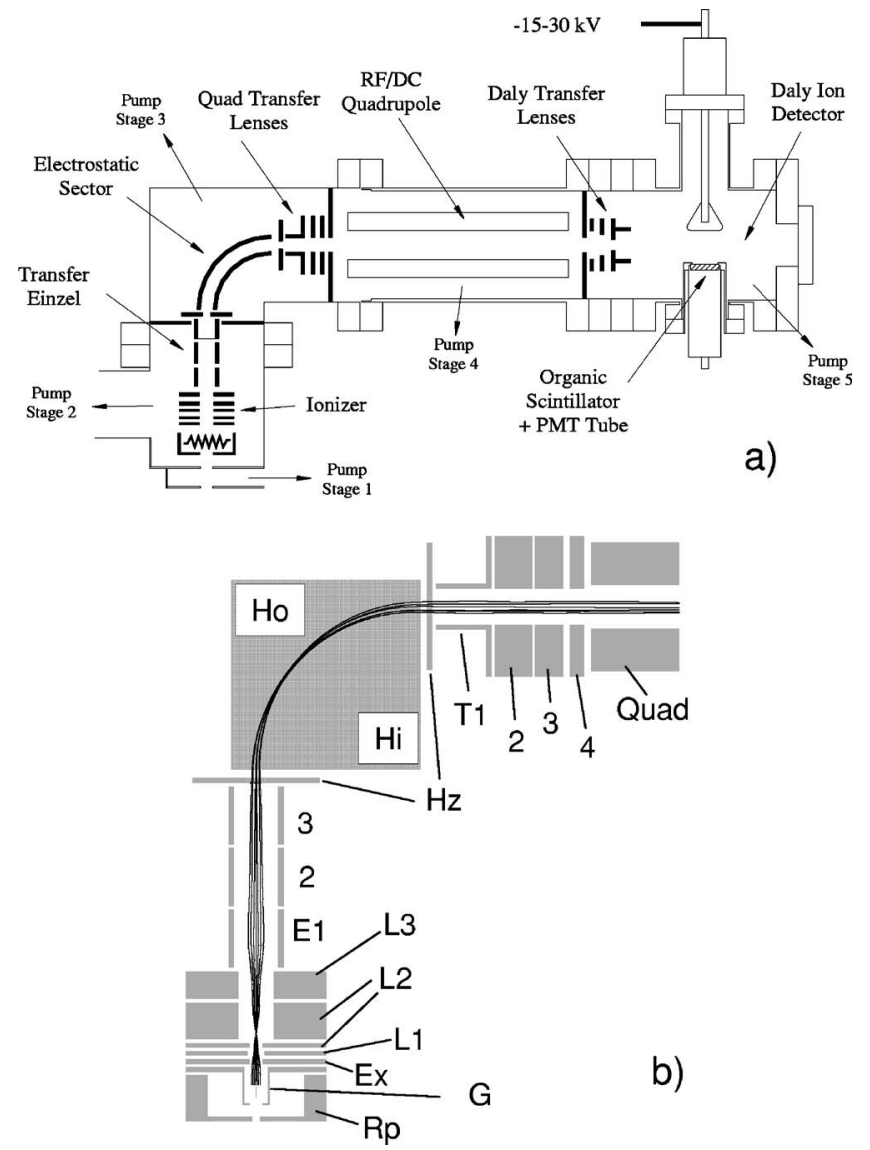

FIG. 5. (a) Simplified schematic of the scattered product detector showing differential pumping stages, ionizer, energy and mass filter, and Daly-type ion counting detector. (b) Example ion trajectory calculation for $50 \mathrm{eV} \mathrm{Ar}^{+}$ at $15 \mathrm{eV}$ pass energy showing various lenses in the scattered product detector $(\mathrm{Rp}=$ repeller, $\mathrm{G}=$ grid, $\mathrm{Ex}=$ ion extractor, $\mathrm{L} 1 \ldots 3=$ ionizer focus, $\mathrm{E} 1 \ldots 3$ $=$ Einzel transfer, $\mathrm{Hz}=\mathrm{Herzog}$ plates, $\mathrm{Ho}, \mathrm{Hi}=$ outer and inner hemispheres, $\mathrm{T} 1 . .4=$ quad transfer, and $\mathrm{Q}=$ quad centerline float). All lenses float off the sector retard voltage used to scan the kinetic energy pass band.

ionizer can be sufficiently "tuned" to provide ionization at a uniform ion creation potential of narrow energy width $(\leqslant 1 \mathrm{eV}) .{ }^{4}$ All lens elements in the ionizer are fully tunable and emission currents up to $10 \mathrm{~mA}$ at $100 \mathrm{eV}$ electron energy are possible. The ionizer itself is positioned directly behind the second skimming aperture $(2 \mathrm{~mm})$ on the back of the first differential pumping stage with the ionizing volume situated only $80 \mathrm{~mm}$ from the sample surface. An Einzel triplet lens system was added to the rear of the ionizer to provide better extraction and imaging of ions on the inlet slit of the electrostatic sector. The triplet lens system floats off the electrostatic sector retard voltage ramp to provide a nearly constant focusing power over all ion energies. SIMION was used to design the lens system and operating voltages to provide uniform transmittance of all ion energies irrespective of retardation level.

For the $90^{\circ}$ electrostatic sector, spherical electrodes (gold-plated oxygen-free high-conductivity copper) with 50 and $65 \mathrm{~mm}$ radii were used, giving a mean sector radius of $57.5 \mathrm{~mm}(\sim 2.25 \mathrm{in}$.$) . Herzog corrector plates were posi-$ tioned at the inlet and exit of the sector to appropriately terminate the deflection field, and a four-element Einzel-type transfer lens assembly is used to transport and tightly focus 
exiting ions onto the entrance aperture of the $\mathrm{rf} / \mathrm{dc}$ quad. The energy filtering action of the sector is accomplished by slowing down or speeding up ions which enter the sector to the pass energy of the analyzer [constant acceptance energy (CAE) mode] by sweeping the retarding voltage from $-E_{\text {pass }}$ kinetic energy $(\mathrm{KE}=0)$ up to some maximum scanned energy. A pass energy of $15 \mathrm{eV}$ was used for most of our scattering experiments because it provided good energy resolution and adequate transport energy through the quadrupole. Both the inlet triplet and four-lens exit system on the sector analyzer were designed through extensive SIMION simulation. An example ion trajectory calculation for a $50 \mathrm{eV} \mathrm{Ar}^{+}$beam retarded to the $15 \mathrm{eV}$ pass energy of the analyzer is shown in Fig. 5(b). Very specific voltage ratios between the inlet and exit lens elements were required for proper focus over a wide range of ion energies. As such, a custom, computer controlled power supply system was built for the sector analyzer, inlet, and exit Einzel lens systems.

For the quadrupole, the dc rod voltages were derived directly from the rf drive to the poles by vacuum tube diodes. This unique feature allowed the entire rod set and match box circuitry to be floated above ground. The ability to artificially move the quad centerline potential above ground was absolutely necessary because the ion flight energy within the quad must ramp with the energy analyzer retard voltageotherwise, the flight energy through the quad is not constant. The centerline quad potential was attached directly to the main retarding voltage ramp of the energy filter. In this way, ions fly through the quad at exactly the pass energy of the energy filter, irrespective of what kinetic energy is being scanned. Finally, to further decrease the residual gas background and prevent ion forming collisions within the quad, a special cryocooled shroud at $30 \mathrm{~K}$ was placed around the quad pole set (not shown).

The extremely small ion signals $\left(10^{-15}-10^{-17}\right.$ Torr effective pressure) that are generated by electron impact ionization of secondary neutrals leaving the target surface require an extremely sensitive, single-ion type counting system. The problem is unavoidable because ionization by electron impact is quite inefficient. The most well-designed magnetically confined ionizers running in space charge limited mode at $10 \mathrm{~mA}$ of emission current can only provide a conversion efficiency of maybe one part in $10^{4} .^{31}$ This dictates that the ion detector must be able to count every single ion that is generated. For this purpose, we developed a hybrid ion counting system based on the approach of Daly. ${ }^{32}$ Ions exiting the quad are "bunched" by a three element immersion lens $(+200 \mathrm{~V},-3 \mathrm{kV},-6 \mathrm{kV})$ at the rear of the quad and they are subsequently accelerated to -15 to $-30 \mathrm{kV}$ by a conversion dynode. When the high energy ions strike the aluminum dynode surface $\left(\sim 45^{\circ}\right.$, angle of maximum secondary electron emission), a shower of secondary electrons (15-30 keV with respect to ground) is created. These secondary electrons, in turn, are accelerated away from the dynode and converted to light $\left(\lambda_{\max }=408 \mathrm{~nm}\right)$ by a plastic scintillator ( $\sim 3-4$ photons $/ e^{-}$for Bicron BC408). Finally, the resulting photon pulses are registered by a special bi-alkali photocathode photomultiplier tube (PMT) with maximum sensitivity at $400-420 \mathrm{~nm}$. The scintillator was metallized on the dynode side by sputter coating with $1500 \AA$ of aluminum to provide a grounded surface and light shield for the PMT. The PMT tube itself was housed inside vacuum with a $\mu$-metal magnetic shield and pressed firmly against the rear of the scintillator. The tube is run in pulse count mode with the photocathode at positive high voltage to further reduce spurious electron pulses.

\section{BEAMLINE PERFORMANCE}

The major goal of our endeavor was to construct a massfiltered ion beam system which could deliver reasonable fluence $\left(100 \mathrm{~s}\right.$ of $\left.\mu \mathrm{A} / \mathrm{cm}^{2}\right)$ at low beam energy $(50-1000 \mathrm{eV})$ for surface scattering studies. The real test of such a system indeed lies in the mass-filtering capability, available current, and scattered product detector performance. As such, we sought to answer several questions, which are addressed in the following sections:

(1) Can isotopically pure beams be generated from a complex plasma gas mixture (i.e., one commonly used for dry etching)?

(2) What is the current delivery versus beam energy?

(3) Is the ion beam energy distribution at the target sufficiently narrow for scattering experiments?

(4) Can the impact energy be tuned easily by floating the entire ICP plasma source above ground?

\section{A. Mass separation}

The mass resolution of the ion beamline system was evaluated by forming isotopically clean ion beams from a complex plasma gas mixture that is typically used for dry etching of $\mathrm{SiO}_{2}$. This situation represents an extreme case of beam contamination and can be used to test the ability of an ion beam system to give high mass resolution and produce clean, pure beams. Figure 6 shows a typical mass sweep of the beams that can be formed by extracting all the ions from a $\mathrm{CF}_{4} / \mathrm{Ar} / \mathrm{O}_{2}$ plasma mixture running at $500 \mathrm{~W}$ plasma power. The plot was formed by sweeping the field strength of both the $60^{\circ}$ sector and $10^{\circ}$ deflector magnets simultaneously via computer control while maintaining the beam energy at $100 \mathrm{eV}$ and beamline transport voltage at $-12 \mathrm{keV}$. The mass exit slit on the $60^{\circ}$ magnet was set to a $3 \mathrm{~mm}$ width and the beam current at the target location was measured with a Faraday cup (500 $\mu \mathrm{m}$ diam inlet aperture). It can be seen that all the ions in the plasma source are easily resolved by the sector magnet and can be transported to the sample as isotopically pure beams for scattering experiments. Higher resolution is possible with smaller exit slit size, but better mass separation is not needed for most of the beams shown. Mass sweeps of this type demonstrate the power of the beamline system for plasma diagnostics as well as a direct feedback mechanism for tuning plasma operation to obtain the highest yield of the ion species of interest.

\section{B. Target current}

One of the most important design criteria for the beamline was high beam current at low impact energy. This is made possible by the accel-decel scheme where ions are cre- 


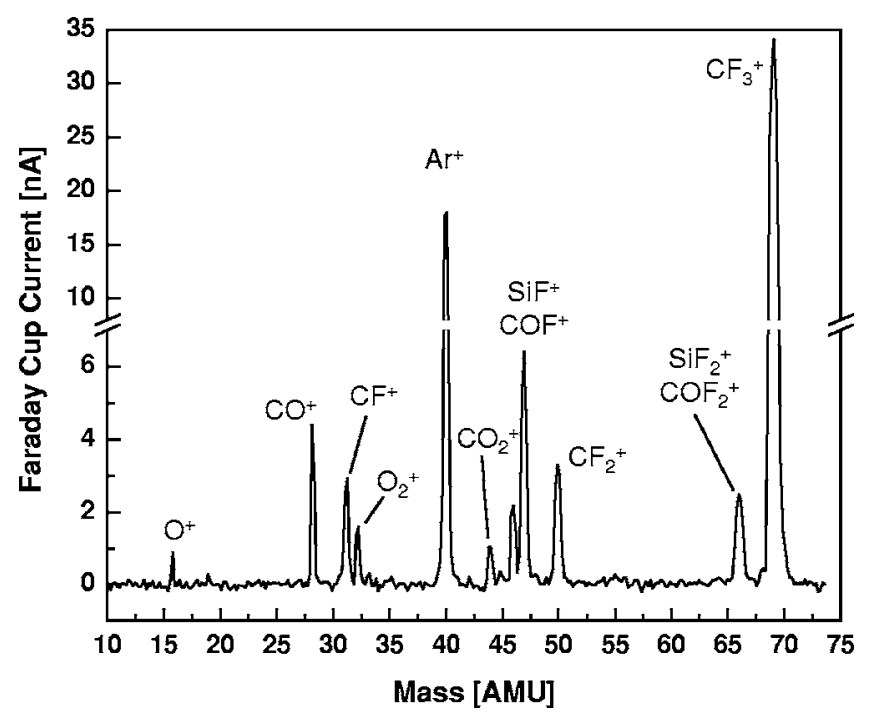

FIG. 6. Beam currents measured via Faraday cup $(0.5 \mathrm{~mm}$ inlet diameter) at the target position for a $\mathrm{CF}_{4} / \mathrm{O}_{2} / \mathrm{Ar}(48: 14: 38)$ plasma running at $3.5 \mathrm{mT}$ and $500 \mathrm{~W}$. Beamline transport voltage was $-12 \mathrm{keV}$ and the mass slit was set to $3 \mathrm{~mm}$ width. $\mathrm{SiF}^{+}$and $\mathrm{SiF}_{2}^{+}$species result from attack of the pyrex plasma reactor used for this experiment. Also, $\mathrm{O}_{2}$ was added to the plasma mix to prevent $\mathrm{CF}_{2}$-like polymer deposition on the reactor walls at high $\mathrm{CF}_{4}$ blending ratios.

ated in the plasma at the impact energy, accelerated to high transport energy, and then decelerated near the target back to their initial creation potential. The success of such a scheme depends on having high ion density in the plasma, efficient extraction, minimal current loss during transport, and proper focus correction during deceleration. However, the entire system cannot deliver high current at low energy unless all of the beamline components function together in unison through proper beam transport between each stage. Thus, overall system performance can be evaluated directly through the available beam current. Typical data for our system are shown in Fig. 7. The ion arrival rate is represented in terms of beam current density on the target delivered through the $2 \mathrm{~mm}$ diam flag aperture (see discussion in Sec. II F). Current density at the target is more useful for direct comparison with an arrival rate of one monolayer per second $\left(1 \mathrm{ML} / \mathrm{s} \sim 320 \mu \mathrm{A} / \mathrm{cm}^{2}\right.$ for $\left.\mathrm{Si}\right)$. Figure 7(a) shows an $\mathrm{Ar}^{+}$ beam extracted from a pure Ar plasma discharge running at $500 \mathrm{~W}$ and 5 mTorr. Atomic and molecular oxygen beams extracted from an $\mathrm{Ar} / \mathrm{O}_{2}$ plasma are also given in panel(b). Argon was added to the oxygen discharge to increase inductive power coupling with the $\mathrm{rf}$ antenna using a mixing ratio of Ar: $\mathrm{O}_{2}$ of 1.3:1 and 5 mTorr operating pressure. The beam currents on these plots were measured for identical extraction conditions (puller and buncher voltages held constant) over all beam energies with the main beamline transport energy at $\sim 13 \mathrm{keV}$. As one might expect, the beam current increases with increasing impact energy until a saturation condition is reached. The saturation current depends strongly on the plasma operating conditions as well as the field strength in the beam extraction region. When the beam energy is lowered below 100-150 eV, the beam current begins to fall off because of excessive space charge spreading during extraction from the plasma and during the beam deceleration step.
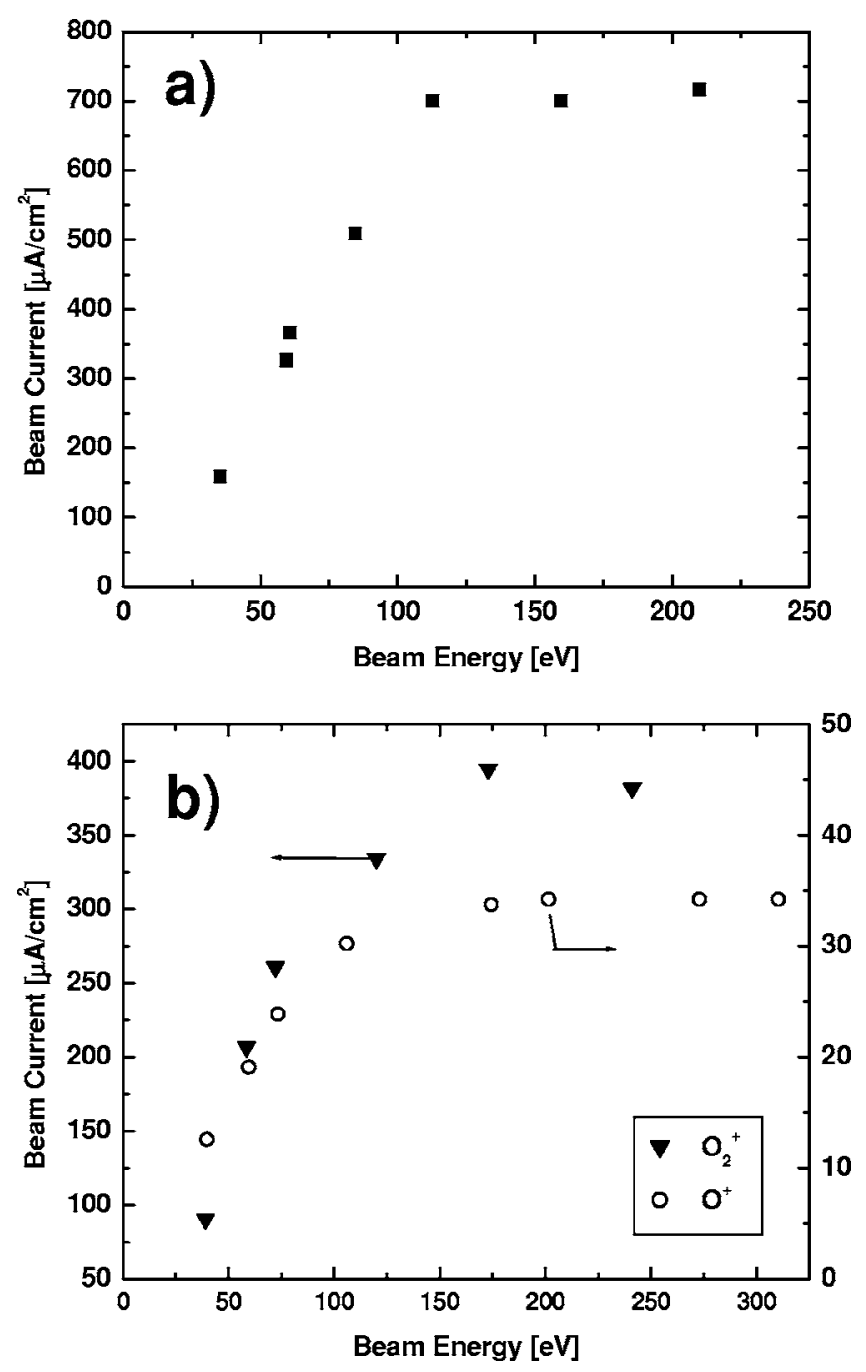

FIG. 7. Current density at the target for: (a) $\mathrm{Ar}^{+}$and (b) $\mathrm{O}_{2}^{+}$and $\mathrm{O}^{+}$ion beams for different final beam energies. In each case, the beamline transport voltage was maintained at $\sim 13 \mathrm{keV}$, decelerator was tuned to optimize beam current through the $2 \mathrm{~mm}$ diam beam flag aperture. A neat Ar plasma and $\mathrm{O}_{2} / \mathrm{Ar}$ plasma at $\sim 500 \mathrm{~W}$ and 3-5 mTorr were used.

In general, higher currents are possible if the ICP plasma is driven harder and stronger extraction conditions are used to compensate the increased space charge density that occurs when ions leave the virtual sheath at the floating extraction aperture (see Sec. II B). Beam currents below $100 \mathrm{eV}$ can also be increased (up to $\sim 1.5$ times) if the decelerator is specifically tuned for stronger focusing action and the steering quad plates directly in front of the target are run significantly positive to pinch the beam inward. The ion fluxes shown for the $\mathrm{Ar}^{+}$and $\mathrm{O}_{2}^{+}$beams are at least $1 \mathrm{ML} / \mathrm{s}$ for $E_{\text {impact }} \geqslant 100 \mathrm{eV}$. This current level into a $2 \mathrm{~mm}$ spot at such low impact energy represents several orders of magnitude higher arrival rate than most mass-filtered ion beam sources. For example, electron impact sources typically used for ion scattering spectroscopy (ISS) (even without mass filtering) can barely approach $0.01-0.1 \mathrm{ML} / \mathrm{s}^{12}$ These sources typically provide up to $100 \mathrm{nA}$ into a beam spot of $1 \mathrm{~mm}$ at 1 $\mathrm{keV}$ with the spot size becoming significantly larger and beam current smaller as the impact energy is lowered. 


\section{Ion beam energy distributions and energy tunability}

The success of any ion beam scattering experiment relies heavily on a well-defined scattering geometry and incident beams with narrow energy spread if the energy distributions of surface scattered products are to be meaningful. Furthermore, tuning the projectile energy provides a direct means of varying the distance of closest approach $\left(R_{\min }\right)$ that occurs during the close encounter between the two colliding nuclei. These two features, tunable energy and narrow width, are fundamental requirements for any ion source and beam system used for scattering studies, especially at low impact energy.

ICP plasma discharges have been shown to have a relatively narrow ion energy distribution function (IEDF) by several different measurement techniques. ${ }^{33,34}$ Typical IEDFs are 5-10 eV FWHM with low- or high-energy tails in some cases. However, an ICP plasma has not been used as a beamline ion source for low- $E$ studies before and most of the beamline experience that exists in the literature (Freeman sources) pertains to much higher impact energies (>1-5 keV), where an energy width of $20-50 \mathrm{eV}$ is usually inconsequential. Therefore, we felt that a concrete measure of the beam energy distribution at the sample location was necessary. Just because the ICP can be tuned to give a narrow IEDF does not mean that the beam hitting the target sample will be narrow as well. Broadening of the distribution due to collisions with background gas atoms in the extraction region and during transport as well as ion creation along the flight path through electrode collisions can potentially pollute the beam hitting the sample. ${ }^{3}$ Any capacitive coupling from the rf drive antenna to the ICP will also cause inherently bimodal beams (IEDF for a capacitive discharge is bimodal). ${ }^{5,14}$ Finally, our technique for adjusting the impact energy, by floating the entire plasma volume above ground with a dc bias, must be tested.

The energy tunability of the ion beamline system was evaluated by measuring the IEDF of the incoming ion beam directly at the target location with the $180^{\circ}$ energy sector analyzer mentioned earlier. A typical energy distribution for both a low and high energy ${ }^{20} \mathrm{Ne}^{+}$beam measured at the target location is given in Fig. 8. The sector was run in CAE mode $\left(E_{\text {pass }}=15 \mathrm{eV}\right)$ while ion energy scans were performed by ramping the retard voltage on the whole analyzer. Figure 8 shows that the beam energy can be varied easily by increasing the dc voltage on the plasma bias plate, where the offset between applied bias and measured energy represents the Ne plasma potential $(\sim 10-12 \mathrm{eV})$. The IEDFs are consistently narrow $(<10 \mathrm{eV}$ FWHM) and peaks are unimodal, indicating that capacitive coupling from the rf antenna is efficiently stopped by the Faraday shield, i.e., power transfer to the plasma electrons is purely inductive. Similar plasma potentials in the $10-20 \mathrm{eV}$ range have been measured by other authors with Langmuir probe techniques for inert gas ICP discharges in the 2-5 mTorr range. ${ }^{35}$ Thus, the beamline can simply transport the plasma IEDF all the way to the sample without significant broadening. A narrow energy distribution for the incoming ion beam is very important because this inherent energy width can be comparable to the

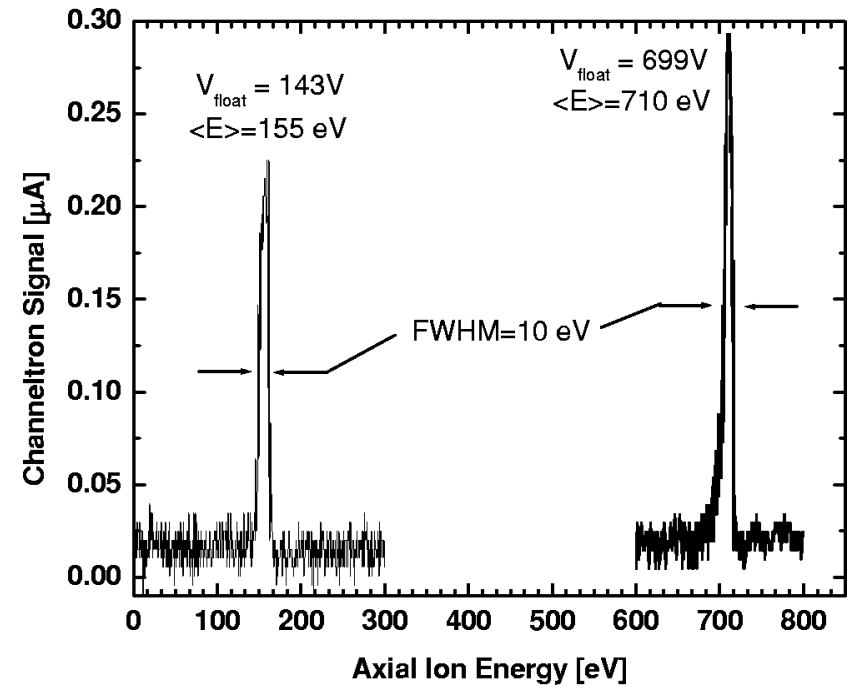

FIG. 8. Ion beam energy distributions for ${ }^{20} \mathrm{Ne}^{+}$measured at the target position using a miniature hemispherical sector energy analyzer with channeltron detector. For each case, the difference between the plasma float potential and the average beam energy $(11-12 \mathrm{~V})$ is dictated by the $\mathrm{Ne}$ plasma self-potential. Narrow FWHMs over a wide impact energy range can be seen.

particle exit energies when hyperthermal projectiles (50-500 $\mathrm{eV}$ ) are scattered from a surface. Also, inelastic energy loss mechanisms typically account for $<10 \%$ of the total loss upon scattering. ${ }^{2}$ Careful measurements of these losses cannot be accomplished if the incident beam energy width is too large. Discrete losses during the close encounter may occur but they can be frequently overshadowed or "smeared out" by an incident energy distribution that is too broad.

\section{Scattered product detector performance}

Energetic ion bombardment of a solid sample generates a whole range of particle fluxes leaving the target surface (see Ref. 36). The major species are sputtered neutrals and secondary ions with kinetic energies of a few eV up to tens of $\mathrm{eV}$. These species are a mix of projectile and target atoms that are generated as a result of multiple collisions and sputtering processes. At higher exit energies, surface atom recoils, and directly scattered projectiles that survive neutralization (or those that are reionized on the exit path from the target surface) are observed. The energy spectrum of these directly scattered species contains information about single collision processes and the energy losses that can occur during the close encounter between the projectile and target nuclei. The inelasticity in these single collisions can manifest itself as electron excitation of the projectile or target atoms, photon generation, or energetic electron release. ${ }^{37} \mathrm{~A}$ product detection system capable of distinguishing the energy spectrum of many of the species leaving the surface could prove very useful in understanding the fundamental processes occurring on the surface during bombardment.

As a test case, the neutral detection capabilities of our system [secondary neutral mass spectroscopy (SNMS)] were evaluated by looking for directly scattered hyperthermal $\mathrm{Ar}^{0}$ from $\mathrm{Ar}^{+}$bombardment of an $\mathrm{Ag}$ surface at $110 \mathrm{eV}$ impact energy. Results of this experiment are shown in Fig. 9. En- 


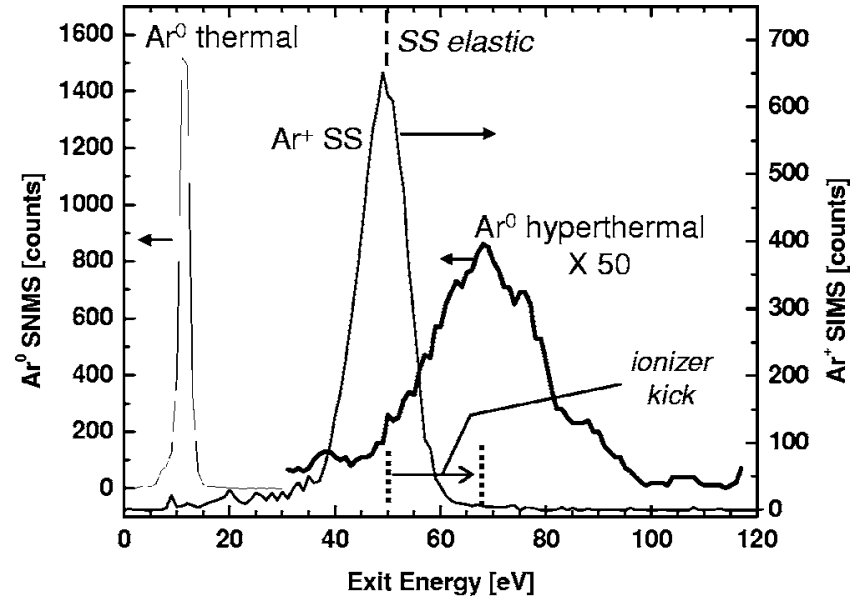

FIG. 9. Energy scans of $\mathrm{Ar}^{0}$ and $\mathrm{Ar}^{+}$exit channels from $\mathrm{Ar}^{+}$scattering off an $\mathrm{Ag}$ target at $110 \mathrm{eV}$ and $90^{\circ}$. Neutrals were detected with the ionizer running at $2 \mathrm{~mA}$ emission current, $70 \mathrm{eV}$ electron energy, and the capacitor deflector in the first pumping stage set to $+200 \mathrm{~V}$. In the hyperthermal $\mathrm{Ar}^{0}$ case, the ion creation potential in the ionizer is $\sim 15 \mathrm{eV}$ above ground, giving the fast neutrals leaving the surface a kinetic energy kick of $15 \mathrm{eV}$ when electron impact ionization occurs. Thus, the single scattered $\mathrm{Ar}^{+}$ which is neutralized to $\mathrm{Ar}^{0}$ by the surface should occur at $\sim 15 \mathrm{eV}$ above the SS position shown for the ion peak.

ergetic Ar neutrals are formed from single collision binary events of $\mathrm{Ar}^{+}$projectiles with $\mathrm{Ag}$ target atoms that are neutralized along the incoming or outgoing portion of the trajectory in the near surface region. Single collisions of $\mathrm{Ar}^{+}$with the surface result in a large fast scattered ion signal near $45-50 \mathrm{eV}$. This energy represents the single scattering events that occur in one binary collision, where the energy transfer can be approximated by the binary collision approximation. ${ }^{2}$ The kinematic factor (energy transfer ratio) for $\mathrm{Ar}^{+}$on $\mathrm{Ag}$ for a $90^{\circ}$ scattering angle is $\sim 0.46$, which would predict $\sim 50 \mathrm{eV}$ exit energy for the $110 \mathrm{eV}$ incident projectile. Also shown are the neutral signals, with one large peak at low energy along with a much smaller, broad $\mathrm{Ar}^{0}$ peak occurring near $65 \mathrm{eV}$. All neutral scans were conducted with the capacitor ion deflector in the first pumping stage set to $+200 \mathrm{~V}$ to prevent any charged species from ever reaching the detector. The ionizer was run at $2 \mathrm{~mA}$ electron emission current with $70 \mathrm{eV}$ electrons and the quadrupole was locked at 40 amu with $\Delta m \sim 1$ amu pass mass width. In addition, the scan was taken in a single pass with $0.5 \mathrm{~s}$ dwell time for each energy bin $(\Delta E=1 \mathrm{eV})$. The large $\operatorname{Ar}^{0}$ peak at low energy represents the residual gas background and thermal species leaving the target which are ionized near the $15 \mathrm{~V}$ grid potential of the ionizer. The $\sim 3 \mathrm{eV}$ shift to lower energy occurs because of the space charge potential depression created in the ionizing volume by the high emission current $(2 \mathrm{~mA}) .{ }^{38}$ The $65 \mathrm{eV}$ neutral peak can be attributed to single-scattered projectiles that are neutralized along the incoming or outgoing scattering trajectory by the Ag surface. This peak is shifted upward by $15-20 \mathrm{eV}$ from the directly scattered ion peak because the ionizing volume is run $15 \mathrm{~V}$ above ground. When fast neutrals enter the ionizer, they are given a "kick" in energy the moment they are converted to ions by electron impact due to the $15 \mathrm{~V}$ accelerating field. A question may arise why the $\operatorname{Ar}^{0}$ exit kinetic energy is not exactly equal the
$\mathrm{Ar}^{+}$exit energy taking into account the $15 \mathrm{eV}$ kick. Fast neutrals seem to appear $\sim 3-5 \mathrm{eV}$ faster than the directly scattered ions. The offset likely occurs because the electron straggling of the projectile on the incoming and outgoing trajectories near the surface is charge state dependent. ${ }^{39}$ It has also been shown by Xu et al. ${ }^{40}$ that the continuous straggling loss, as represented by the Oen and Robinsen approach, ${ }^{41}$ depends on the particle charge state.

The neutral experiments conducted with our scattered product detector indicate that having an energy filter between the ionizer and the rest of the detection system can be successfully used to separate residual gas neutrals from those originating from the target. In addition, the peak energy positions of both the ion and neutral signals can be identified and make good sense when the operation of the detection system is clearly understood. As well, the detection of neutrals generated at the target surface has been demonstrated, suggesting that scattering experiments with reactive systems (where most of the reaction products are neutral) will be possible.

\section{APPLICATIONS}

\section{A. Elastic scattering at low energy}

Low energy $\mathrm{He}^{+}$ion scattering has been used for a long time to determine the composition and structure of the topmost atomic layers of a target surface (for example, see Ref. 42). This technique is based on the binary collision approximation (BCA) model, where the projectile is deflected by a sequence of pairwise interactions with individual target atoms. Each deflection event is assumed to be totally elastic, so the energy transfer during the hard collision event can be described by conservation of energy and momentum. As such, the projectile energy after a single collision can be simply calculated using the well-known "kinematic factor" $(K):^{2}$

$$
E_{\text {exit }}=K E_{0}=\frac{1}{(1+\gamma)^{2}}\left(\cos \theta_{L}+\sqrt{\gamma^{2}-\sin ^{2} \theta_{L}}\right)^{2} E_{0},
$$

where $E_{0}$ and $E_{\text {exit }}$ are the incident and scattered projectile energies, $\gamma$ is the target-to-projectile mass ratio $\left(M_{T} / M_{P}\right)$, and $\theta_{L}$ is the lab scattering angle. Application of the BCA theory to $\mathrm{He}^{+}$ISS using $\mathrm{keV}$ impact energies is beyond debate. ${ }^{39,42}$ However, systematic studies of scattering phenomena involving heavier inert ions at lower impact energies have not been so widespread. To this end, it seems most natural that we use our beamline system to investigate BCA predictions at low collision energies. Indeed, any discussion of inelastic energy losses that occur in hard collision events (i.e., electronic excitation of projectile or target) must first include an assessment of how realistic the BCA model is at low energy. In addition, it has already been mentioned that equipment issues, such as scattering angle change with impact energy, broad IEDFs for the incident beam, and high surface neutralization rates frequently hamper low energy scattering experiments. Evaluating the BCA over a wide range of target-to-projectile mass ratio serves as a test platform to assess if such effects are important for our beamline scattering system. 

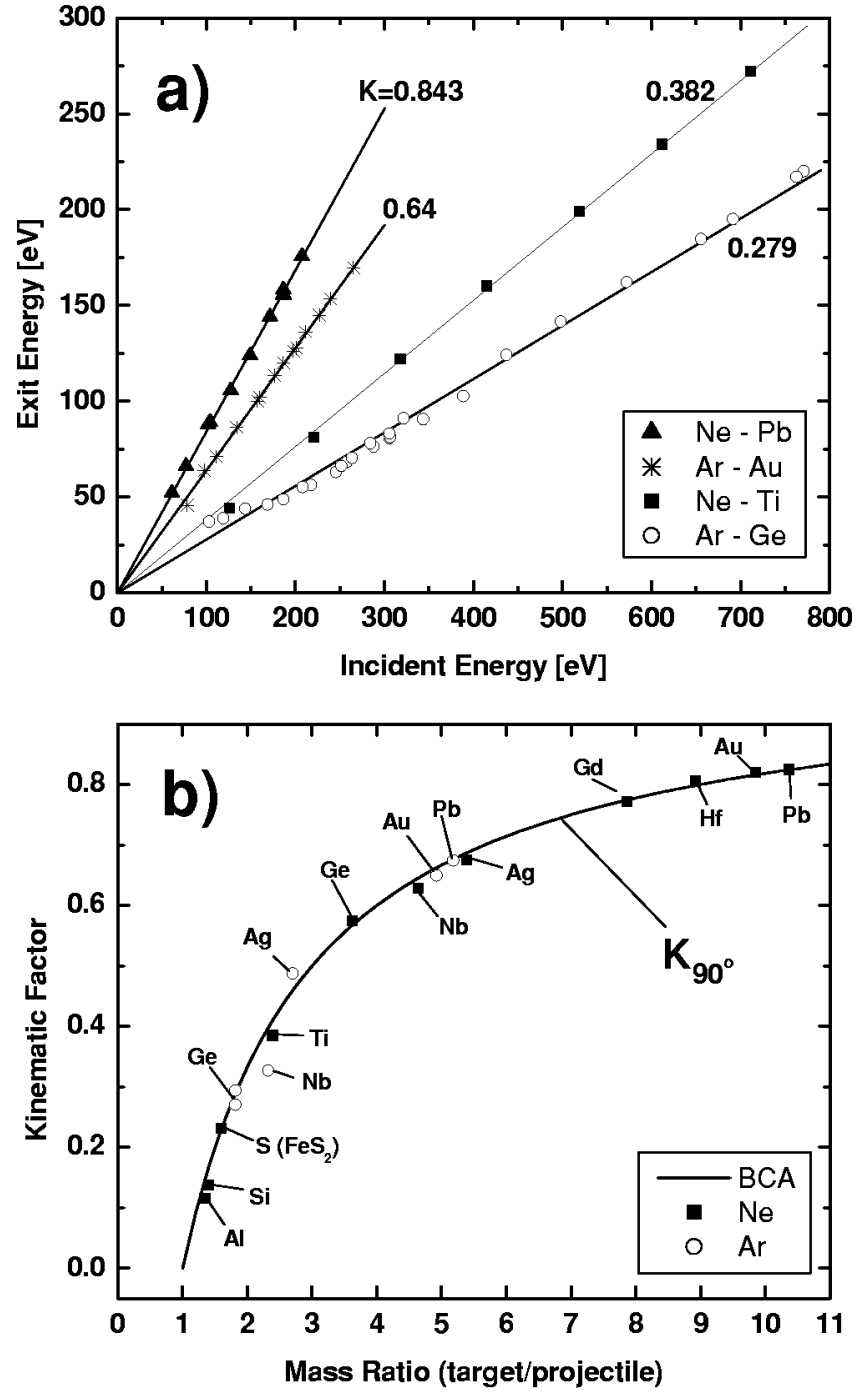

FIG. 10. (a) Experimental exit energies for single-scattered ${ }^{20} \mathrm{Ne}^{+}$and $\mathrm{Ar}^{+}$ off several targets showing the constant kinematic energy transfer factor. (b) Summary of experimental kinematic factors for collision energies between 50 and $1000 \mathrm{eV}$, measured from the slope of the $E_{\text {exit }}$ vs $E_{0}$ data. The theoretical prediction from the BCA model for $90^{\circ}$ scattering is given by the line. For $\mathrm{Al}$ and Si targets, only the data below $E_{0}=500 \mathrm{eV}$ was used for the $K$-factor determination

Figure 10(a) shows the measured exit energy for singlescattered ${ }^{20} \mathrm{Ne}^{+}$and $\mathrm{Ar}^{+}$off several target surfaces $[\mathrm{Pb}, \mathrm{Au}$, $\mathrm{Ti}, \mathrm{Ge}(111)]$ at $90^{\circ}$ lab angle for collision energies starting at $\sim 50 \mathrm{eV}$. Regression lines using a hard zero intercept are also given, allowing an experimental kinematic factor to be determined directly from the slope. For these experiments, each target was sputter cleaned (5 $\mathrm{keV} \mathrm{Ar}^{+}, 60^{\circ}$ incidence), annealed, and amorphized with the low- $E$ projectile beam at $300 \mathrm{eV}$ for $\sim 15 \mathrm{~min}$ before taking data. In each case, the exit energy dependence is seen quite linear with collision energy, even down to the low energy range. The small upturn in the Ge data $\left(E_{\text {exit }}>E_{\text {exit,BCA }}\right)$ is likely caused by increased multiple deflection events (one glancing, one near $90^{\circ}$ ) due to the underlying (111) crystal structure being insufficiently amorphized at $E_{0}<150 \mathrm{eV}$.

Experimental $K$ factors for $\sim 50-1000 \mathrm{eV}$ impact were also measured for a wide variety of target materials using ${ }^{20} \mathrm{Ne}^{+}$and $\mathrm{Ar}^{+}$projectiles. These results are given in Fig.
10 (b) as a function of target-to-projectile mass ratio, along with the BCA predicted $K$ value for single scattering at $90^{\circ}$ [Eq. (1)]. Agreement between the experimental data and theory is excellent, despite the oversimplified view of the collision process given by the BCA model. It should be noted here that the $K$ factor determination for $\mathrm{Ne}-\mathrm{Al}$ and $\mathrm{Ne}-\mathrm{Si}$ are based on impact energies $<400-500 \mathrm{eV}$ only. In the next section, we will see that inelastic energy losses become important for the $\mathrm{Ne}-\mathrm{Al}$ and $\mathrm{Ne}-\mathrm{Si}$ systems once a critical distance of closest approach has been reached in the binary hard collision. We can also determine that the constant $K$ factor seen in all cases verifies that the lab scattering angle does not change as the impact energy is varied for our system.

\section{B. Charge exchange involving $\mathrm{Ne}^{+}$with light targets}

We have shown in the previous section that the BCA model is quite successful in predicting energy transfer for $\mathrm{Ne}^{+}$projectiles with impact energies between $\sim 50$ and 1000 $\mathrm{eV}$ on a variety of targets. However, inelastic loss processes can sometimes occur where the translational $\mathrm{KE}$ of the incoming ion is converted into electronic excitation or ionization of the atoms in the colliding pair. ${ }^{37}$ The existence of such channels is often seen as shifts in exit energies of the projectile or target recoil from their elastic positions, changes in the scattered particle charge state, or emission of characteristic electrons and photons as excited states (created in the hard collision) decay (see Ref. 37 for a review). In particular, inelastic losses, high ion yields $\left(>50 \% \mathrm{Ne}^{+}\right.$off $\left.\mathrm{Mg}\right){ }^{43-45}$ and multiply-charged scattered projectiles $\left(\mathrm{Ne}^{++}\right.$and $\mathrm{Ne}^{3+}$ off $\mathrm{Mg}, \mathrm{Al}$, and $\mathrm{Si})^{40,46-50}$ have been seen for single binary collisions involving $\mathrm{Ne}^{+}$projectiles at $\mathrm{keV}$ impact energies. Such "richness" in the scattering behavior is intimately linked to local charge exchange phenomena which occur as the atomic orbital (AO) states of the collision partners quantum mechanically mix into hybrid molecular orbitals (MOs) during the hard collision step (the Fano-Lichten MO mechanism). ${ }^{51}$ Although many studies have been conducted with $\mathrm{Ne}^{+}$on $\mathrm{Mg}, \mathrm{Al}$, and $\mathrm{Si}$ at high collision energies, little experimental data exist for the threshold region at low impact energy where local charge exchange processes and inelastic losses begin to occur. We present a brief summary here of our experiments on $\mathrm{Ne}^{+}$collisions with light targets ( $\mathrm{Mg}, \mathrm{Si}, \mathrm{Al}$, and P) for impact energies $<1400 \mathrm{eV}$ to emphasize why tunable incident energy, as well as mass and energy filtering of scattered products, is necessary. Details of these scattering experiments are presented elsewhere. ${ }^{52}$ Simultaneous mass and energy dispersion of scattered products is highly advantageous because the energy distributions of $\mathrm{Ne}^{+}(m / e=20)$ and $\mathrm{Ne}^{++}(m / e=10)$ can be measured separately-eliminating signal overlap and confusion from multiple charge states which can occur for electrostatic-only and TOF-type analyzers (see Refs. 45 and 49 for overlap issues).

Exit energies of $\mathrm{Ne}^{+}$and $\mathrm{Ne}^{++}$resulting from single binary collisions of $\mathrm{Ne}^{+}$with an $\mathrm{Al}$ target from $\sim 100$ to 1400 $\mathrm{eV}$ are shown in Fig. 11(a), along with the BCA prediction $(K=0.149)$ for single scattering $(\mathrm{SS})$ at $90^{\circ}$. The total $\mathrm{Ne}^{+}$ scattered intensity is also given, where the raw detector counts in the lab frame have been converted to a term pro- 

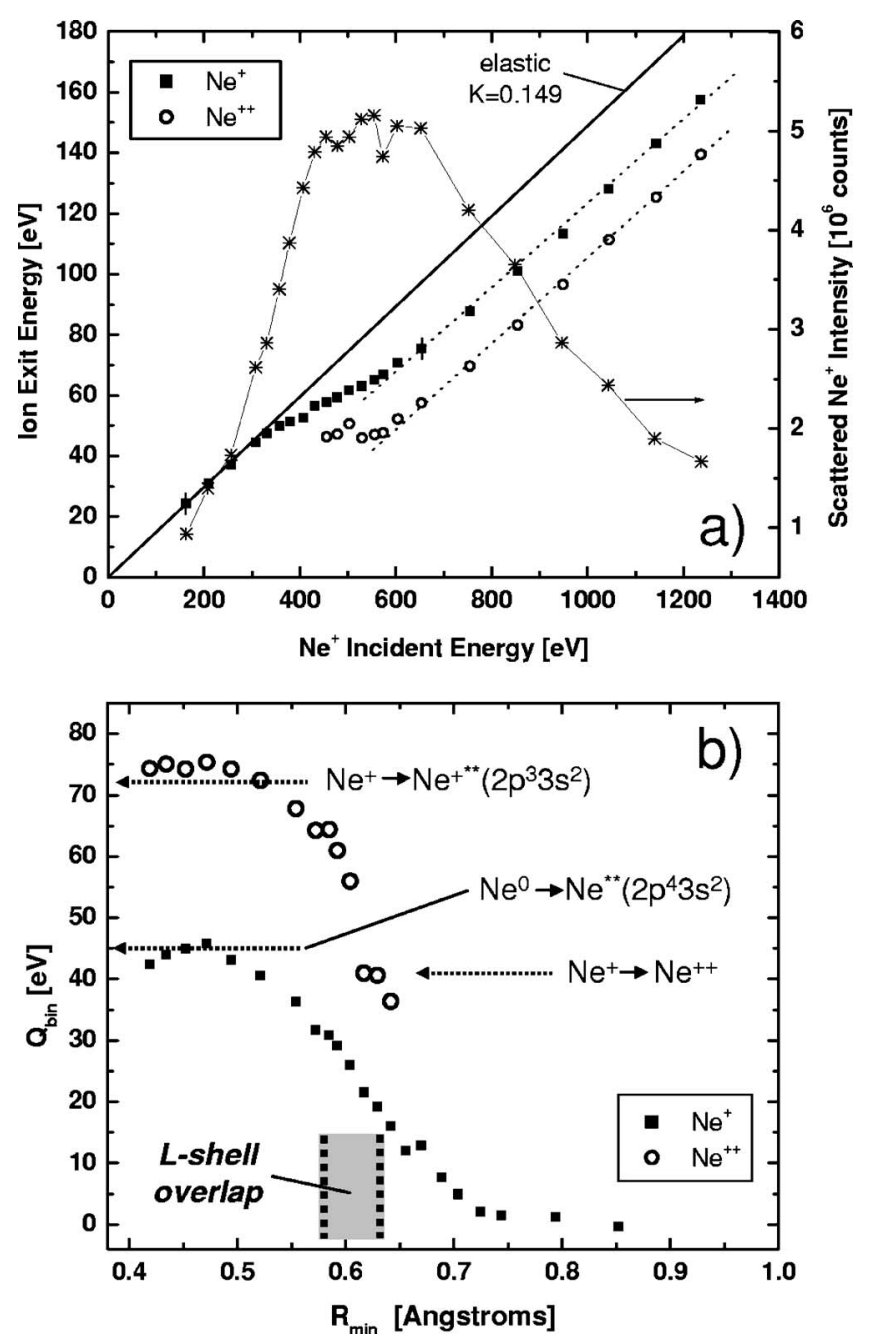

FIG. 11. (a) Exit energies of $\mathrm{Ne}^{+}$and $\mathrm{Ne}^{++}$resulting from single binary collisions of ${ }^{20} \mathrm{Ne}^{+}$projectiles with polycrystalline $\mathrm{Al}$ for $90^{\circ}$ lab scattering angle in specular reflection. Elastic scattering behavior for a single collision is indicated with $K=0.149$. Error bars $( \pm 5 \mathrm{eV})$ on the energy data are partially shown to avoid clutter. (b) Binary collision inelasticities determined from the data in (a). Energy requirements for various electronic excitations of $\mathrm{Ne}^{0}$ and $\mathrm{Ne}^{+}$are shown, along with the theoretically predicted overlap distance of the $n=2$ orbitals of the collision partners (grey area). The collision $R_{\min }$ has been calculated using the Thomas-Fermi-Molière potential.

portional to the ion yield by normalizing by the incident beam current and scattering cross section. ${ }^{53}$ Two regions are seen where the $\mathrm{Ne}^{+}$and $\mathrm{Ne}^{++}$exit energies are markedly different. At low impact energy (region 1), the $\mathrm{SS} \mathrm{Ne}^{+}$exit appears totally elastic and $\mathrm{Ne}^{++}$is not seen in the scattered ion spectrum. Since the collision $R_{\min }$ (distance of closest approach) is relatively large $(>0.8 \AA)$ at low- $E$ impact, straggling losses are small (a few eV maximum) and significant overlap of the core-shell atomic orbitals of the collision partners does not occur. As such, elastic scattering behavior for $\mathrm{Ne}^{+}$is seen and no excitation channels exist to form $\mathrm{Ne}^{++}$ (due to MO promotion in the hard collision). However, as the collision energy is raised (region 2), a transition occurs where the $\mathrm{Ne}^{+}$exit becomes inelastic and $\mathrm{Ne}^{++}$is suddenly generated at $\sim 470 \mathrm{eV}$ with a large energy offset from the SS elastic line. At this threshold (minimum $R_{\min }$ requirement), three phenomena occur simultaneously in the scattered ion spectrum: (1) $\mathrm{Ne}^{++}$generation; (2) reversal of the $\mathrm{Ne}^{+}$yield trend with impact energy; and (3) significant hard collision losses in the $\mathrm{Ne}^{+}$and $\mathrm{Ne}^{++}$exit channels. The $R_{\text {min }}$ value where $\mathrm{Ne}^{++}$first occurs $(470 \mathrm{eV}=0.64 \AA$ Thomas-FermiMolière or $0.56 \AA$ Ziegler-Bierszack-Littmark interatomic potentials) agrees well with the theoretical distance required for $L$-shell orbital overlap for the $\mathrm{Ne}-\mathrm{Al}$ collision pair $(0.57$ $\AA){ }^{54}$ This observation suggests that a local charge exchange process, driven by atomic orbital overlap of the $2 s$ and $2 p$ shells of $\mathrm{Ne}$ and $\mathrm{Al}$, is likely responsible. Going one step further, binary collision inelasticities can be evaluated by adjusting the lab frame energy loss to the center-of-mass frame and accounting for electron straggling on the incoming and outgoing trajectory paths (see Ref. 52 for details). This inelasticity data $\left(Q_{\text {bin }}\right)$ for $\mathrm{Ne}-\mathrm{Al}$ is given in Fig. 11(b), where saturation-like behavior for both the $\mathrm{Ne}^{+}$and $\mathrm{Ne}^{++}$exit channels can be seen. Furthermore, we can identify the saturation energy loss values $\left(\sim 40-45 \mathrm{eV}\right.$ for $\mathrm{Ne}^{+}, 70-75 \mathrm{eV}$ for $\left.\mathrm{Ne}^{++}\right)$ as associated with double excitation events, which occur in the hard collision step as the $4 f \sigma$ MO from the Ne $2 p$ is highly promoted at small $R_{\min }$

$$
\begin{aligned}
& \mathrm{Ne}^{0}\left(2 p^{6}\right)+41-45 \mathrm{eV} \rightarrow \mathrm{Ne}^{* *}\left(2 p^{4} 3 s^{2}\right), \\
& \mathrm{Ne}^{+}\left(2 p^{5}\right)+69-72 \mathrm{eV} \rightarrow \mathrm{Ne}^{+* *}\left(2 p^{3} 3 s^{2}\right) .
\end{aligned}
$$

In the first case, $\mathrm{Ne}^{+}$is Auger neutralized to $\mathrm{Ne}^{0}$ in the incoming path to the surface and is doubly excited by transferring two electrons out of the promoted $2 p_{z}\left(4 f \sigma^{2} \mathrm{MO}\right)$ as it crosses the $3 s . \mathrm{Ne}^{* *}$ can leave the hard collision intact $\left(\mathrm{Ne}^{* *}\right.$ lifetime $\left.>1.5 \times 10^{-14} \mathrm{~s}\right)^{55}$ and autoionize in vacuum far from the surface region. For the latter, a projectile ion which has survived neutralization on the incoming path is doubly excited in the same manner but significantly more excitation energy is required to promote two electrons in the ion. Autoionization decay of $\mathrm{Ne}^{+* *}$ then results in the $\mathrm{Ne}^{++}$exit channel, which shows $\sim 70 \mathrm{eV}$ hard collision inelastic loss.

The reversal in $\mathrm{Ne}^{+}$yield with impact energy is discussed in depth in Ref. 52, but it is clear that a transition from nonlocal neutralization at low- $E$ impact (Auger type) to $R_{\text {min }}$-dependent collision induced neutralization occurs as the $R_{\text {min }}$ decreases. The critical $R_{\text {min }}$ requirement for the yield reversal is intimately tied to the $4 f \sigma \mathrm{MO}$ promotion as well. If the incoming $\mathrm{Ne}^{+} 2 p$ vacancy evolves as $3 d \pi^{4} 4 f \sigma^{1}$, resonant transfer from the target bands to the promoted $4 f \sigma^{1}$ can neutralize the projectile, causing the total $\mathrm{Ne}^{+}$yield to decrease. This mechanism, because it involves resonant transfer, should only be operable if the $4 f \sigma$ is promoted enough so as to cross the target conduction band energy levels. As such, a strong $R_{\min }$ dependence, or minimum impact energy threshold, would be seen. This is indeed the case.

\section{Reactive scattering of $\mathrm{CF}_{2}^{+} / \mathrm{CF}_{3}^{+}$off $\mathrm{Si}$}

Scattering studies using reactive projectiles on $\mathrm{Si}(100)$ were conducted as preliminary work towards a larger goal of understanding the fundamental energetics and reaction 
mechanisms that occur during reactive ion bombardment of $\mathrm{Si}-$ as applied to dry plasma etching processes. These experiments with pure, mass-filtered beams of reactive projectiles in the low energy range from 50 to $500 \mathrm{eV}$ are, in fact, one of the main driving forces behind our ion beamline system. The $50-500 \mathrm{eV}$ range is required in plasma etching to provide momentum assist to surface chemical reactions and stimulate etch product removal from the wafer surface without causing damage to the substrate from heavy sputtering at high impact energies. ${ }^{5}$ The experiments presented here only provide a taste of the complex processes occurring in $\mathrm{CF}_{x}$ etching of $\mathrm{Si}$, but they demonstrate why one needs a single ion species at well defined energy along with broad based detection capabilities of the particle flux leaving the target surface. Fundamental understanding of the complex mechanisms involved requires all the beamline components: (1) robust, high density ion source, (2) mass-filtered ion beamline, (3) low tunable energy, (4) high current, and (5) detection of mass and energy of ions and neutrals leaving the substrate surface.

As a first step, we looked at the ion species leaving the target surface for $\mathrm{CF}_{3}^{+}$and $\mathrm{CF}_{2}^{+}$bombardment of $\mathrm{Si}(100)$ as a function of impact energy to give hints about the influence of ion energy on removal of surface reaction products in $\mathrm{Si} / \mathrm{SiO}_{2}$ etching environments. Although this experiment seems rather simple, it has not been done before with a single ion species and simultaneous product detection. $\mathrm{CF}_{3}^{+}$ and $\mathrm{CF}_{2}^{+}$beams were formed from $\mathrm{CF}_{4} / \mathrm{Ar} / \mathrm{O}_{2}$ plasmas running at $500-700 \mathrm{~W}$ and $\sim 5 \mathrm{mTorr}$, giving target currents $>200 \mu \mathrm{A} / \mathrm{cm}^{2}\left(\mathrm{CF}_{3}^{+}\right)$and $\sim 50 \mu \mathrm{A} / \mathrm{cm}^{2}\left(\mathrm{CF}_{2}^{+}\right)$. For this scattering experiment, we sought to answer two questions: (1) what is the fate of the molecular ion as it hits the surface? and (2) which ion species are preferentially released from the reactive $\mathrm{SiC}_{x} \mathrm{~F}_{y}$ layer that forms on the $\mathrm{Si}$ surface during bombardment? Figure 12 summarizes the results for $\mathrm{CF}_{3}^{+}$and $\mathrm{CF}_{2}^{+}$bombardment of $\mathrm{Si}$ at $90^{\circ}$ lab angle $\left(45^{\circ}\right.$ incidence) for impact energies from $\sim 50$ to $500 \mathrm{eV}$. As shown, the main ion species leaving the surface are $\mathrm{CF}^{+}, \mathrm{C}^{+}, \mathrm{Si}^{+}$, and surprisingly $-\mathrm{SiF}^{+}$. At the lowest impact energy $(\sim 70 \mathrm{eV})$, some $\mathrm{CF}_{3}^{+}$and $\mathrm{CF}_{2}^{+}$are seen, but they quickly disappear above $100 \mathrm{eV}$ impact energy. The presence of $\mathrm{CF}_{3}^{+}$at low energy [Fig. 12(a)] is likely molecular ion survival while the $\mathrm{CF}_{2}^{+}$may be caused by F-atom abstraction of the incoming projectile (dissociative scattering) or physical sputtering of $\mathrm{CF}_{2}$-like species from the surface. An analogy is drawn here to $\mathrm{CF}_{3}^{+}$scattering off fluorinated liquid surfaces, ${ }^{56}$ where the perfluoropolyether (PFPE) surface is terminated entirely by $-\mathrm{CF}_{3}$ and $-\mathrm{F}$ species with the ether oxygen atoms buried beneath the surface. ${ }^{57,58}$ Collision phenomena should be similar because it is a generally held belief that $\mathrm{CF}_{x}$ etching of $\mathrm{Si}$ proceeds through a reactive $\mathrm{SiC}_{x} \mathrm{~F}_{y_{5}}$ layer with dangling $-\mathrm{CF}_{x}$ and $-\mathrm{SiF}_{y}$ moieties on the surface. ${ }^{5}$ For the PFPE case, the predominant ion exit for $\mathrm{CF}_{3}^{+}$scattering at $>250 \mathrm{eV}$ impact was $\mathrm{CF}^{+}$, with little or no $\mathrm{CF}_{2}^{+}$or $\mathrm{CF}_{3}^{+}$. Our preliminary work echoes this behavior as well. What is interesting at energies above $100 \mathrm{eV}$ in our case is the rise of $\mathrm{C}^{+}$and $\mathrm{SiF}^{+}$ exit channels. The large increase in $\mathrm{SiF}^{+}$from the surface suggests that as the impact energy gets higher, more projectile $\mathrm{F}$ atoms react to form dangling $\mathrm{SiF}_{x}$ species which are
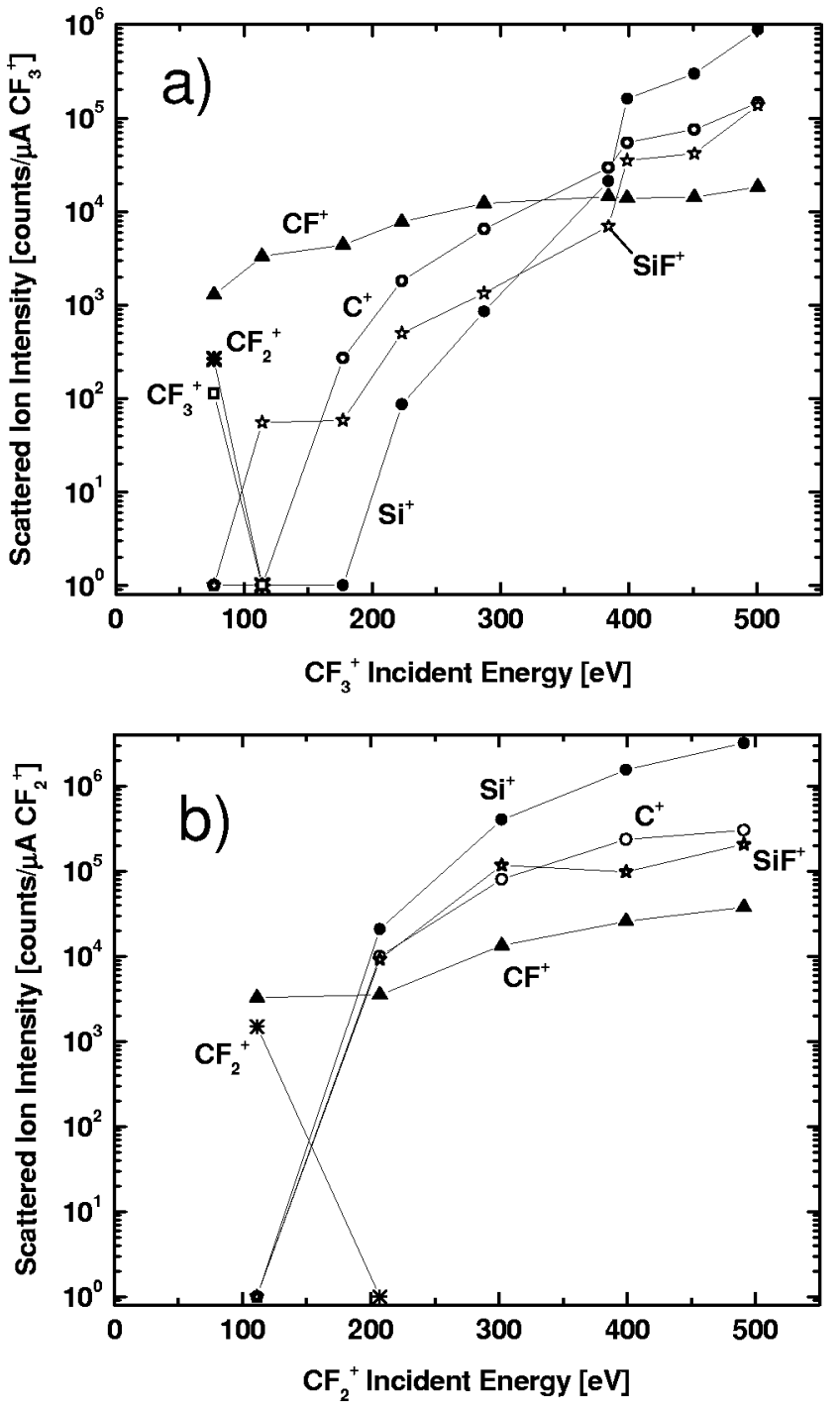

FIG. 12. Charged exit channels leaving an $\mathrm{Si}(100)$ surface for: (a) $\mathrm{CF}_{3}^{+}$and (b) $\mathrm{CF}_{2}^{+}$projectiles. $\mathrm{SiF}_{2}^{+}$and $\mathrm{SiF}_{3}^{+}$ion species were not seen in the scattered ion spectrum for any impact energy tested. The total scattered ion intensity has been normalized by the incident beam current and was obtained by integrating the detector counts of each species (quad at fixed mass) obtained during an energy sweep of the hemispherical sector. $\mathrm{CF}_{4} / \mathrm{O}_{2} / \mathrm{Ar}$ plasmas running at $1-5$ mTorr and $500-700 \mathrm{~W}$ were used.

sputtered away as $\mathrm{SiF}^{+}$only (if they exit the surface in a charged state). We specifically looked for $\mathrm{SiF}_{2}^{+}$and $\mathrm{SiF}_{3}^{+}$leaving the surface and did not detect any signal for all the impact energies tested. It is curious why $\mathrm{SiF}^{+}$is the only charged Si-containing species leaving the surface, but one could explain such an observation as being due to an F-deficient surface. Finally, the spectra show the onset of $\mathrm{Si}^{+}$ for impact energies above $\sim 200 \mathrm{eV}$, which is a sure sign that the increased momentum of the projectile is beginning to just sputter the target surface.

This simple study gives a flavor for the physical scattering behavior as well as some of the chemical reactions that are occurring on the surface during bombardment with just one incident ion species. It is also clear from this one experiment that complex scattering behavior, especially for a reactive system, absolutely requires mass filtering of the particle flux leaving the target surface to sort out all the exit chan- 
nels. Turning on the ionizer to look at the neutrals along with energy analysis of the scattered flux will add a whole new dimension to fundamental scattering studies.

\section{DISCUSSION}

In this article, we have demonstrated that high fluxes (100s of $\mu \mathrm{A} / \mathrm{cm}^{2}$ ) of a single ion species at low energy $(50-1000 \mathrm{eV})$ can be delivered to an UHV environment for surface scattering experiments by developing an ICP-based ion beamline system. It was seen that high current at low energy requires several key components: (1) high density plasma-based ion source operating at low pressure; (2) beam extraction near the space charge limit sustainable by the plasma sheath; (3) an accel-decel transport scheme; and (4) allowances for beam quality correction at every step of the transport process (extraction, mass filtering, neutral stripping, and most importantly, deceleration). We have also introduced a floating scheme where large portions of the ion beam transport line (vacuum chambers, valves, feedthrus, power supplies, etc.) are biased at many $\mathrm{kVs}$ below ground. This approach avoids the problem of high-voltage isolation in vacuum, where space is tight and pumping conductance must be maximized; at the same time, the continuous floating envelope around the ion column inherently shields the beam from decelerating fields which can deteriorate quality and rob current.

Detailed studies of the energy distributions (IEDF) and tunability of decelerated ion beams at the target showed that: (1) the ICP has an inherently narrow energy spread $( \pm 5 \mathrm{eV}$ FWHM, about the unbiased plasma potential) when power coupling is purely inductive; (2) floating the entire plasma volume above ground externally is effective in changing the ion creation potential; and (3) it is absolutely necessary to measure the beam IEDF at the target to appropriately account for how the plasma self-potential changes the final impact energy. In addition, we have seen that low, tunable incident energy as well as mass and energy filtering of products leaving the target surface are extremely advantageous and enable a wide range of ion-surface interactions to be studied. Such capabilities allow the collision kinematics, charge exchange, and chemistry occurring on the target surface to be separated by fully analyzing the scattered flux. Furthermore, in a variety of cases, such as multiple charge states or a complex mix of reactive exit channel species leaving the target surface, the ionizer-electrostatic sectorquadrupole detector package can easily resolve overlapping signals, a common problem with time-of-flight or electrostatic-only systems. In this way, complex scattering phenomena can be investigated from several different measurement perspectives simultaneously.

\section{ACKNOWLEDGMENTS}

The authors would like to express their gratitude to Mike Roy in the Caltech Chemistry Machine Shop for his design assistance and tireless hours of fabrication which made the beamline system a reality. This research work was funded in part by the NSF (Grant No. CTS-0317397) and Applied Materials. Additionally, M. Gordon would like to thank the Intel
Foundation and Applied Materials for personal scholarship support.

${ }^{1}$ W. Ensinger, Nucl. Instrum. Methods Phys. Res. B 127/128, 796 (1997).

${ }^{2}$ J. W. Rabalais, Principles and Applications of Ion Scattering Spectrometry: Surface Chemical and Structural Analysis (Wiley, New Jersey, 2003).

${ }^{3}$ A. H. Al-Bayati, D. Marton, S. S. Todorov, K. J. Boyd, J. W. Rabalais, D. G. Armour, J. S. Gordon, and G. Duller, Rev. Sci. Instrum. 65, 2680 (1994).

${ }^{4}$ M. J. Gordon, thesis, California Institute of Technology, 2003.

${ }^{5}$ M. Lieberman and A. Lichtenberg, Principles of Plasma Discharges and Materials Processing (Wiley, New York, 1994).

${ }^{6}$ Charged Particle Optics, Part C: Very High Density Beams, edited by A. Septier (Academic, New York, 1983).

${ }^{7}$ J. D. Lawson, The Physics of Charged Particle Beams, 2nd ed. (Clarendon, Oxford, 1988).

${ }^{8}$ J. S. Gordon, A. Bousetta, J. A. van den Berg, D. G. Armour, R. Kubiak, and E. H. C. Parker, Nucl. Instrum. Methods Phys. Res. B 55, 314 (1991).

${ }^{9}$ J. S. Gordon, D. G. Armour, S. E. Donnelly, J. A. van den Berg, D. Marton, and J. W. Rabalais, Nucl. Instrum. Methods Phys. Res. B 59/60, 312 (1991).

${ }^{10}$ J. Ishikawa, Y. Takeiri, and T. Takagi, Rev. Sci. Instrum. 57, 1512 (1986).

${ }^{11}$ F. Qin, X. Wang, Z. Liu, Z. Yao, Z. Ren, S. Su, W. Jiang, and W. M. Lau, Rev. Sci. Instrum. 62, 2322 (1991).

${ }^{12}$ Handbook of Ion Sources, edited by B. Wolf (CRC Press, New York, 1995).

${ }^{13}$ J. H. Freeman, W. Temple, D. Beanland, and G. A. Gard, Nucl. Instrum. Methods 135, 1 (1976).

${ }^{14}$ J. H. Keller, Plasma Sources Sci. Technol. 5, 166 (1996).

${ }^{15}$ W. L. Johnson, US Patent No. 5,234,529.

${ }^{16}$ A. J. T. Holmes and E. Thompson, Rev. Sci. Instrum. 52, 172 (1981).

${ }^{17}$ Focusing of Charged Particles, edited by A. Septier (Academic, New York, 1967), Vol. 2.

${ }^{18}$ D. Dahl, SIMION 3D v. 7.0 (Idaho National Engineering and Environmental Laboratory, Idaho Falls, 2000).

${ }^{19}$ M. Inghram and R. Hayden, A Handbook on Mass Spectroscopy, Nuclear Science Series, Report No. 14 (National Academy of Sciences, Washington, D.C., 1954).

${ }^{20}$ N. Coggeshall, J. Appl. Phys. 18, 855 (1947).

${ }^{21}$ H. Enge, Rev. Sci. Instrum. 32, 278 (1963).

${ }^{22}$ R. Souda, K. Yamamoto, W. Hayami, T. Aizawa, and Y. Ishizawa, Phys. Rev. Lett. 75, 3552 (1995).

${ }^{23}$ R. Souda, K. Yamamoto, W. Hayami, T. Aizawa, and Y. Ishizawa, Surf. Sci. 363, 139 (1996).

${ }^{24}$ J. Amano, P. Bryce, and R. P. W. Lawson, J. Vac. Sci. Technol. 13, 591 (1976).

${ }^{25}$ G. E. Thomas, L. J. Beckers, J. J. Vrakking, and B. R. De Koning, J. Cryst. Growth 56, 557 (1982).

${ }^{26}$ W. M. Lau, X. Feng, I. Bello, S. Sant, K. K. Foo, and R. P. W. Lawson, Nucl. Instrum. Methods Phys. Res. B 59/60, 316 (1991).

${ }^{27}$ O. Tsukakoshi, S. Shimizu, S. Ogata, N. Sasaki, and H. Yamakawa, Nucl. Instrum. Methods Phys. Res. B 55, 355 (1991).

${ }^{28}$ S. Shimizu, O. Tsukakoshi, S. Komiya, and Y. Makita, Jpn. J. Appl. Phys., Part 1 24, 1130 (1985).

${ }^{29}$ I. Yamada, H. Inokawa, and T. Takagi, Nucl. Instrum. Methods Phys. Res. B 6, 439 (1985).

${ }^{30}$ K. Wittmaack, Surf. Sci. 345, 110 (1996).

${ }^{31}$ Atomic and Molecular Beam Methods, edited by G. Scoles (Oxford University Press, New York, 1988), Vol. 1.

${ }^{32}$ N. R. Daly, Rev. Sci. Instrum. 31, 264 (1959); see also Y. T. Lee, J. D. McDonald, P. R. LeBreton, and D. R. Herschback, ibid. 40, 1402 (1969).

${ }^{33}$ E. A. Edelberg, A. Perry, N. Benjamin, and E. S. Aydill, J. Vac. Sci. Technol. A 17, 502 (1999).

${ }^{34}$ M. Sobolewski, J. Olthoff, and Y. Wang, J. Appl. Phys. 85, 3966 (1999).

${ }^{35}$ J. Hopwood, C. R. Guarnieri, S. J. Whitehair, and J. J. Cuomo, J. Vac. Sci. Technol. A 11, 147 (1993).

${ }^{36}$ D. Lipinsky, R. Jede, O. Ganshow, and A. Benninghoven, J. Vac. Sci. Technol. A 3, 2007 (1985).

${ }^{37}$ S. R. Kasi, H. Kang, C. S. Sass, and J. W. Rabalais, Surf. Sci. Rep. 10, 1 (1989).

${ }^{38}$ UTI Instruments, Notebook 73-4 (UTI Instruments, San Jose, CA, 1992).

${ }^{39}$ H. Neihus, W. Heiland, and E. Taglauer, Surf. Sci. Rep. 17, 213 (1993).

${ }^{40}$ F. Xu, G. Manicò, F. Ascione, A. Bonanno, A. Oliva, and R. A. Baragiola, 
Phys. Rev. A 57, 1096 (1998).

${ }^{41}$ O. Oen, and M. Robinsen, Nucl. Instrum. Methods 132, 647 (1976).

${ }^{42}$ A. W. Czanderna and D. M. Hercules, Ion Spectroscopies for Surface Analysis (Plenum, New York, 1991).

${ }^{43}$ J. W. Rabalais, CRC Crit. Rev. Solid State Mater. Sci. 14, 319 (1988)

${ }^{44}$ J. W. Rabalais, J. N. Chen, R. Kumar, and M. Narayana, J. Chem. Phys. 12, 6489 (1985)

${ }^{45}$ O. Grizzi, M. Shi, H. Bu, J. W. Rabalais, and R. A. Baragiola, Phys. Rev. B 41, 4789 (1990).

${ }^{46}$ O. Grizzi, E. A. Sánchez, S. Lacombe, and V. A. Esaulov, Phys. Rev. B 68, 085414 (2003).

${ }^{47}$ B. Hird, R. A. Armstrong, and P. Gauthier, Phys. Rev. A 49, 1107 (1994).

${ }^{48}$ R. Souda, K. Yamamoto, W. Hayami, T. Aizawa, and Y. Ishizawa, Phys. Rev. Lett. 75, 3552 (1995).

${ }^{49}$ G. Manicò, F. Ascione, N. Mandarino, A. Bonanno, P. Ricardi, P. Zoccali, A. Oliva, M. Camarca, and F. Xu, Surf. Sci. 392, L7 (1996).

${ }^{50}$ F. Ascione, G. Manicò, A. Bonanno, A. Oliva, and F. Xu, Surf. Sci. 394,
L145 (1997)

${ }^{51}$ M. Barat and W. Lichten, Phys. Rev. A 6, 211 (1972).

${ }^{52}$ M. J. Gordon, J. Mace, and K. P. Giapis, Phys. Rev. A 72, (in print) (2005).

${ }^{53}$ The scattered ion signal is normalized by the beam current and corrected for the change in scattering cross section with impact energy using the Thomas-Fermi-Molière potential.

${ }^{54}$ J. Slater, Quantum Theory of Atomic Structure (McGraw-Hill, New York, 1960), Vol. 1, p. 210.

${ }^{55}$ R. Morgensten, A. Niehaus, and G. Zimmermann., J. Phys. B 13, 4811 (1980).

${ }^{56}$ W. R. Koppers, J. H. M. Beijersbergen, T. L. Weeding, P. G. Kistemaker, and A. W. Kleyn, J. Chem. Phys. 107, 10736 (1997).

${ }^{57}$ M. E. King, G. M. Nathanson, M. A. Hanning-Lee, and T. K. Minton, Phys. Rev. Lett. 70, 1026 (1993).

${ }^{58}$ M. E. King, M. E. Saecker, and G. M. Nathanson, J. Chem. Phys. 101, 2539 (1994). 